\title{
A synthesis of carbon in international trade
}

\author{
G. P. Peters ${ }^{1}$, S. J. Davis ${ }^{2,3}$, and R. Andrew ${ }^{1}$ \\ ${ }^{1}$ Center for International and Environmental Research Oslo - CICERO, PB 1129 Blindern, 0318 Oslo, Norway \\ ${ }^{2}$ Department of Global Ecology, Carnegie Institution of Washington, Stanford, CA 94305, USA \\ ${ }^{3}$ Department of Earth System Science, University of California, Irvine, CA 92697, USA
}

Correspondence to: G. P. Peters (glen.peters@ cicero.uio.no)

Received: 26 February 2012 - Published in Biogeosciences Discuss.: 29 March 2012

Revised: 10 July 2012 - Accepted: 23 July 2012 - Published: 23 August 2012

\begin{abstract}
In a globalised world, the transfer of carbon between regions, either physically or embodied in production, represents a substantial fraction of global carbon emissions. The resulting emission transfers are important for balancing regional carbon budgets and for understanding the drivers of emissions. In this paper we synthesise current understanding in two parts: (1) $\mathrm{CO}_{2}$ emissions embodied in goods and services that are produced in one country but consumed in others, and (2) carbon physically present in fossil fuels, petroleum-derived products, harvested wood products, crops, and livestock products. We describe the key differences between studies and provide a consistent set of estimates using the same definitions, modelling framework, and consistent data. We find the largest trade flows of carbon in international trade in 2004 were fossil fuels $(2673 \mathrm{MtC}, 37 \%$ of global emissions), $\mathrm{CO}_{2}$ embodied in traded goods and services (1661 MtC, $22 \%$ of global emissions), crops (522 MtC, $31 \%$ of total harvested crop carbon), petroleum-based products $(183 \mathrm{MtC}, 50 \%$ of their total production), harvested wood products $(149 \mathrm{MtC}, 40 \%$ of total roundwood extraction), and livestock products ( $28 \mathrm{MtC}, 22 \%$ of total livestock carbon). We find that for embodied $\mathrm{CO}_{2}$ emissions, estimates from independent studies are robust, and that differences between individual studies are not a reflection of the uncertainty in consumption-based estimates, but rather these differences result from the use of different production-based emissions input data and different definitions for allocating emissions to international trade. After adjusting for these issues, results across independent studies converge to give less uncertainty than previously assumed. For physical carbon flows there are relatively few studies to be synthesised, but differences between existing studies are due to the method of allocating to international trade, with some studies using "apparent con-
\end{abstract}

sumption" as opposed to "final consumption". While results across studies are sufficiently robust to be used in further applications, more research is needed to understand differences and to harmonise definitions for particular applications.

\section{Introduction}

Sources and sinks of carbon dioxide $\left(\mathrm{CO}_{2}\right)$ are usually allocated to countries and industries according to the emissions and uptake that occur within their administered territory (IPCC, 2006). Territory-based emissions inventories are required for input into climate models, and, from a climatepolicy perspective, countries and industries have more power to monitor and regulate their territorial emissions. However, allocation schemes are a human construct, and different allocation schemes may serve different purposes (Caldeira and Davis, 2011). For example, when there is international trade between regions, it is possible to adjust the territorial-based emission inventories to obtain consumption-based inventories by adding the emissions associated with imports and subtracting the emissions associated with exports (Munksgaard and Pedersen, 2001; Peters, 2008; Peters and Hertwich, 2008a; Peters et al., 2009). While most research on consumption-based emission inventories has focused on $\mathrm{CO}_{2}$ emissions from fossil fuel combustion (Peters and Hertwich, 2008b; Hertwich and Peters, 2009; Davis and Caldeira, 2010; Davis et al., 2011; Peters et al., 2011b), international trade is also important in accounting for emissions from land use (Hubacek and Giljum, 2003), forestry (Mayer et al., 2005; Kastner et al., 2011a), biomass more generally (Krausmann et al., 2008; Erb et al., 2009), and constructing regional carbon budgets (Ciais et al., 2007, 2008). Due to 
the continued growth in international trade relative to other macro-economic variables (e.g. Gross Domestic Product), it is increasingly important to accurately quantify emissions associated with traded goods and services (Peters et al., 2009, 2011b).

In the case of $\mathrm{CO}_{2}$ emissions from fossil fuel combustion and industrial processes, $\mathrm{CO}_{2}$ emitted during the production of goods and services that are used for final consumption are said to be "embodied" in these goods and services. Several recent studies have highlighted the magnitude and importance of international trade in transferring embodied emissions between regions (Peters and Hertwich, 2008b; Hertwich and Peters, 2009; Nakano et al., 2009; Davis and Caldeira, 2010; Peters et al., 2011b; Davis et al., 2011; Wiebe et al., 2012). The transfer of embodied carbon is highly relevant for understanding emission drivers (Le Quéré et al., 2009; Peters et al., 2011b) and evaluating proposed climate policies (Peters et al., 2009; Davis and Caldeira, 2010; Davis et al., 2011). There are well-established methods and literature for estimating embodied carbon that consider complex supply chains and can be applied at both the country and global level (Wiedmann et al., 2007; Wiedmann, 2009). Current areas of research usually focus on improving data, harmonising methods, and making analyses more policyrelevant (Tukker et al., 2009; Peters and Solli, 2010; Wiedmann et al., 2011). Several initiatives are underway to construct better and more consistent databases (see Table 1 in Peters et al., 2011a).

Of additional interest to the carbon cycle and policy community are the physical flows of carbon between regions, because these flows may affect regional carbon budgets and land use. The physical flows of carbon are sometimes called lateral carbon flows or horizontal displacements (Ciais et al., 2007; Ciais et al., 2008). These physical flows are in the form of reduced carbon that will later be oxidised, consumed as food, or otherwise utilised. Several studies have modelled the trade of carbon present in harvested wood products, crops, and food with applications for regional carbon budgets (Ciais et al., 2007; Ciais et al., 2008), and more generally for biomass (Haberl et al., 2007; Krausmann et al., 2008;Erb et al., 2009; Kastner et al., 2011a, b) and fossil fuel (Bringezu et al., 2004; Davis et al., 2011; Bruckner et al., 2012) flows between regions. In addition to carbonbudget and land-use studies, physical carbon flows are also important for emission inventories that include biomass carbon (Cowie et al., 2006). Relative to the literature on embodied emissions, there are considerably fewer studies tracking trade in biomass or fossil fuels, and the methods are often less developed. For instance, these studies often focus on "apparent consumption" which generally considers direct trade flows without processing (Ciais et al., 2007; Erb et al., 2009), or only a limited level of processing (Kastner et al., 2011b). There have been several studies on fossil fuel trade using apparent consumption (Bringezu et al., 2004;Dittrich and Bringezu, 2010; Steinberger et al., 2010), while Davis et al. (2011) and Bruckner et al. (2012) use more detailed models with processing. Davis et al. (2011) report the only study to consider fossil fuel extraction and trade in terms of carbon content, and consider the processing of primary energy into secondary energy. In general, there has been more data and method development presented in the literature on embodied carbon flows compared to physical carbon flows.

The aim of this paper is to provide consistent estimates of carbon in international trade, including both emissions embodied in traded goods and services as well as physical flows of reduced carbon, using a single modelling framework. We compare our results to existing studies. In the case of embodied carbon, we perform a larger synthesis of previous global studies to determine the range in independent estimates. We also highlight key results that are robust across all studies. In the case of physical flows of carbon, we expect to find large differences with previous studies that have included less processing (apparent consumption) compared to the more detailed modelling of global supply chains. Since apparent consumption is used in most regional carbon budgets, our results might have implications for balancing carbon budgets.

The paper is structured as follows. First, we give an overview of the terminology used in the analysis and discuss different definitions of consumption. Second, we describe the method and data used. Third, we analyse embodied carbon with a synthesis of studies and additional calculations to understand the differences between estimates. Fourth, we provide detailed and consistent estimates of physical flows of carbon, covering fossil fuels, petroleum-derived products (plastic, fertiliser, etc.), harvested wood products, crops, and livestock products. And finally, we discuss our findings and outline future work. Our analysis is a part of the REgional Carbon Cycle Assessment and Processes $\left(\operatorname{RECCAP}^{1}\right)$, and we present our results for the RECCAP regions (Canadell et al., 2011), and on occasion, for some specific countries where the detail is beneficial.

\section{Description of methods and data}

We use a well-established method to re-allocate emissions from a territorial perspective to international trade flows and ultimately to a consumption perspective. We consider carbon associated with both household activities and the industrial production of goods and services. Emissions by industry are re-allocated along the global supply chain from the point of production to the point of consumption, which may be in a different region and sector. This section gives an overview of the relevant definitions, methods and data.

\footnotetext{
${ }^{1}$ http://www.biogeosciences-discuss.net/special_issue83.html
} 
Table 1. A summary of the trends in three time-series studies of consumption-based emission estimates for key countries and regions (Peters et al., 2012; Wiebe et al., 2012; Lenzen et al., 2012). Comparisons are shown over the common time periods of each estimate (a) 1995-2005, (b) 1990-2009. Differences in the production growth rates are evident in the consumption growth rates.

\begin{tabular}{|c|c|c|c|c|c|c|}
\hline \multirow[b]{2}{*}{ (a) } & \multicolumn{3}{|c|}{ Production-based emissions growth rate (\%/yr) } & \multicolumn{3}{|c|}{ Consumption-based emissions growth rate $(\% / y r)$} \\
\hline & $\begin{array}{l}\text { Peters et al. } \\
\text { (1995-2005) }\end{array}$ & $\begin{array}{l}\text { Lenzen et al. } \\
(1995-2005)\end{array}$ & $\begin{array}{l}\text { Wiebe et al. } \\
(1995-2005)\end{array}$ & $\begin{array}{l}\text { Peters et al. } \\
(1995-2005)\end{array}$ & $\begin{array}{l}\text { Lenzen et al. } \\
(1995-2005)\end{array}$ & $\begin{array}{l}\text { Wiebe et al. } \\
(1995-2005)\end{array}$ \\
\hline EU27 & -0.2 & 0.3 & 0.4 & 0.4 & 0.7 & 1.4 \\
\hline Japan & 0.5 & 0.7 & 0.7 & -0.2 & 0.8 & 0.3 \\
\hline United States of America & 0.4 & 0.9 & 1.0 & 1.5 & 1.5 & 1.9 \\
\hline China & 5.5 & 5.8 & 4.9 & 4.6 & 5.4 & 4.0 \\
\hline Russian Federation & -0.3 & -1.5 & 0.1 & 0.1 & -0.2 & -0.5 \\
\hline India & 3.8 & 3.5 & 3.7 & 3.4 & 3.6 & 3.5 \\
\hline (b) & $\begin{array}{l}\text { Peters et al. } \\
(1990-2010)\end{array}$ & $\begin{array}{l}\text { Lenzen et al. } \\
(1990-2009)\end{array}$ & & $\begin{array}{l}\text { Peters et al. } \\
(1990-2009)\end{array}$ & $\begin{array}{l}\text { Lenzen et al. } \\
(1990-2009)\end{array}$ & \\
\hline EU27 & -0.4 & -0.2 & & 0.1 & 0.2 & \\
\hline Japan & 0.4 & 0.5 & & 0.4 & 0.9 & \\
\hline United States of America & 0.5 & 0.8 & & 1.3 & 1.3 & \\
\hline China & 6.0 & 6.3 & & 4.8 & 6.0 & \\
\hline Russian Federation & -1.8 & -3.1 & & -1.2 & -2.0 & \\
\hline India & 4.8 & 5.0 & & 4.4 & 5.0 & \\
\hline
\end{tabular}

\subsection{Multi-regional input-output analysis (MRIOA)}

Most studies of carbon embodied in international trade recommend accounting for the supply chain using multi-region input-output analysis (MRIOA) (Minx et al., 2009; Wiedmann, 2009; Peters, 2010a). We will first clarify the distinction between physical and economic accounting approaches to carbon flows before we describe MRIOA in more detail.

\subsubsection{Physical and economic approaches to consumption}

There are two main definitions of consumption (and hence trade) in environmental applications, "apparent consumption" and "final consumption", and these can produce significantly different results. The difference between the two definitions is subtle but important.

Many physical accounting approaches are based on the concept of "apparent consumption" (Ciais et al., 2007; Haberl et al., 2007; Ciais et al., 2008; Erb et al., 2009; Krausmann et al., 2008; Kastner et al., 2011a, b). Apparent consumption is fundamentally connected to physical goods, and is defined as the amount of a product produced within a region plus imports minus exports. It is generally assumed that there is no processing or transformation of products ${ }^{2}$. Thus, products are assumed to be consumed in the state in which they were imported and without any further processing; that is, no distinction is made between intermediate consumption and final consumption.

In contrast, methods based on standard environmentaleconomic accounts (United Nations et al., 1993; SEEA,

\footnotetext{
${ }^{2}$ Some exceptions exist (Kastner et al., 2011b).
}

2003) usually adhere to the economic concept of "final consumption". Final consumption is defined in the System of National Accounts ${ }^{3}$ (SNA) as "the goods and services used up by individual households or the community to satisfy their individual or collective needs or wants" (United Nations et al., 1993). Final consumption is distinct from intermediate consumption which is defined as the "goods and services consumed as inputs by a process of production... [which] may be either transformed or used up by the production process" (United Nations et al., 1993). Thus, final consumption is the end of the supply chain where goods and services undergo no further processing to other goods and services, while intermediate consumption continually processes goods and services until they reach final consumption. This processing may happen in a variety of different sectors and regions, and the processing may transform or use up goods or services. Studies that include a supply chain necessarily require a differentiation between intermediate and final consumption to avoid double counting (Gallego and Lenzen, 2005).

The distinction between apparent and final consumption can be illustrated with an example, and we consider timber which can be processed into paper, furniture, or other goods and services. The apparent consumption of timber is given by the regional production of timber added to imported timber and then exported timber is subtracted. Apparent consumption does not consider transformation of timber into furniture, paper, or other goods and services. For final consump-

\footnotetext{
${ }^{3}$ The System of National Accounts is used worldwide to produce consistent economic accounts, including the calculation of Gross Domestic Product.
} 
tion, it is necessary to split timber into the timber that is used directly in final consumption (e.g. to build a house) and the timber which is used indirectly in intermediate consumption by undergoing further processing to furniture, paper, or other goods and services. For the final consumption of furniture by a household, the timber may have been "transformed" into the furniture or "used up" as paper in the furniture factory. The final consumption of services is treated in the same way, but in this case the timber is always "used up" in the supply chain.

A variant of the final consumption approach, known as Emissions Embodied in Bilateral Trade (EEBT), limits the level of processing to national borders (Peters, 2008; Peters and Hertwich, 2008b). The EEBT approach only distinguishes between final and intermediate consumption domestically, and not globally. The advantage of this approach is that at national borders the distinction between final and intermediate consumption is not made, and hence the exports are analogous to bilateral trade statistics (Peters, 2008). While EEBT accounts only domestic emissions embodied in exports, thereby analysing less of the global supply chain, the total global emissions are the same since both final and intermediate consumption are added together.

The different definitions of consumption and allocation of emissions to international trade will be discussed below in the relevant model comparisons, and, through these comparisons, we will discuss in more detail the differences between the methods. Our primary method of allocation is based on final consumption using multi-region input-output analysis (MRIOA) as recommended in other studies (Minx et al., 2009; Wiedmann, 2009; Peters, 2010a).

\subsubsection{Multi-regional input-output analysis (MRIOA)}

Input-Output Analysis (IOA) is a top-down method specifically designed to enumerate and study supply chains (Leontief, 1936) and has been applied to environmental problems since about 1970 (Ayres and Kneese, 1969; Leontief, 1970). IOA is grounded in economic statistics and describes the relationships between all regions and sectors in the database. Since the method is top-down, full emission coverage is obtained and the method allocates emissions along supply chains to provide a link between producers and consumers, or exporters and importers. Methods to study multiple regions and global supply chains were developed early (Isard, 1951; Oosterhaven, 1984) and are now one of the primary methods to study environmental repercussions arising globally (Wiedmann et al., 2007; Wiedmann, 2009). Input-output data are a key component of many economic models, and the data is widely available, including for some key developing countries (Narayanan and Walmsley, 2008). Even though MRIOA is generally applied at the country and sector level rather than product or company level, as in Life Cycle Assessment (LCA), MRIOA has the important advantage of representing the entire global economic structure, including all trade linkages, and can be used to analyse large bundles of goods simultaneously (Peters, 2010a).

There are a number of options for the allocation of bunker fuels, which are used for international transport, but for environmental-economic accounting the European Commission recommends they be allocated to the country of residence of the institute operating the vessel (European Commission, 2009). Thus, emissions from bunker fuels would be allocated to the territorial-based emissions, and then ultimately to final consumption via the international trade in services (Peters et al., 2011a).

All our analysis is performed for one calendar year (2004). For the case of harvested wood products, crops, fossil fuels, and similar, we assume that products move along the international supply chain within one year (that is, there is no change in storage). As an example, if a forest is harvested in one country, and several countries process the product along the global supply chain before it is consumed as paper, then we assume this all occurs within one year. While this will not be strictly true, our assumption implicitly assumes the imbalance at the start of the calendar year balances with the imbalance at the end of the calendar year.

The multi-region input-output table (MRIOT) used in this paper is based on the Global Trade Analysis Project (GTAP) database (Narayanan and Walmsley, 2008) version 7.1 , representing the world economy in 2004. The GTAP database "combines detailed bilateral trade, transport and protection [tarrifs, quotas, etc] data characterizing economic linkages among regions, together with individual country input-output databases which account for inter-sectoral linkages within regions" (Narayanan and Walmsley, 2008). In each region and each year, the economy is divided into 57 economic sectors and three final consumers (households, government, capital investments). The world is divided into 112 countries and regions. The method to convert the GTAP database into an MRIOT is described elsewhere (Peters et al., 2011a). The dataset and method has been applied in several peer-reviewed publications (Peters and Hertwich, 2008b; Hertwich and Peters, 2009; Andrew et al., 2009; Peters et al., 2011b). Hereafter, we refer to our model as the GTAPMRIO.

We allocate emissions to country $\mathrm{X}$ using the following definitions:

- Production: Emissions occurring on administered territories over which $\mathrm{X}$ has jurisdiction (territorial-based emissions);

- Exports: The production-based emissions occurring within $\mathrm{X}$ to produce exports to both intermediate and final consumption and hence including the domestic supply chain only;

- Imports: The emissions in each country (other than X) required to produce final consumption in $\mathrm{X}$ and including the global supply chain; 
- Consumption: The global emissions required to produce the final consumption in $\mathrm{X}$ and including the global supply chain.

These components are then combined as: Consumption $=$ Production - Exports + Imports.

\subsection{Input data for externalities in production}

MRIOA reallocates the "externalities" (here, carbon and $\mathrm{CO}_{2}$ emissions) that occur in production along the global supply chain to consumption. Thus, the MRIOT remains the same, but different externalities are allocated along the supply chain differently depending on the sector where the emissions occur. For example, emissions in the agricultural sector may get allocated to food consumption, while emissions in the steel sector may get allocated to manufactured products. The following sub-sections describe the externality data used in our analysis.

\subsubsection{Energy and feedstock data}

We use the energy and feedstock data from GTAP (Lee, 2008; Narayanan and Walmsley, 2008), but updated for GTAP version 7.1. The GTAP energy and feedstock data is derived from International Energy Agency (IEA) data, but modified to be consistent with the economic data used in the GTAP database (Narayanan and Walmsley, 2008).

\subsubsection{Carbon dioxide data}

We use several different $\mathrm{CO}_{2}$ emission datasets in the analysis below to show the importance of variations in this input dataset. The $\mathrm{CO}_{2}$ datasets are from CDIAC (Carbon Dioxide Information Analysis Center) (Boden et al., 2011), the UNFCCC (United Nations Framework Convention on Climate Change) (2012), EDGAR (Emissions Database for Global Atmospheric Research) (European Commission, 2011), GTAP (Lee, 2008), and an updated version of the GTAP data (Peters et al., 2011a). These datasets, and their differences, are described in more detail in the model comparisons.

\subsubsection{Forestry data}

The Food and Agriculture Organisation (FAO) provides data on the extraction of different forestry products (FAO, 2012c, b). We only consider the extraction of roundwood (FAO code 1861) and use the GTAP-MRIO to estimate the products that are produced from roundwood and potentially entering international trade. Since we consider all products containing roundwood, directly and indirectly, we have covered a broader spectrum of processed wood products than appears in the FAO database. Roundwood can be broadly split into fuelwood (FAO code 1629), charcoal (FAO code 1630), and industrial roundwood (FAO code 1865). Since fuelwood and charcoal are primarily for domestic uses, and often in the informal economy (Kastner et al., 2011a; FAO, 2012c), we only include industrial roundwood in our analysis.

To convert from cubic metres in the FAO data to carbon, we take several steps. First, we divide the industrial roundwood into coniferous (FAO code 1866) and nonconiferous (FAO code 1867) and convert from cubic metres to dry-weight in tonnes using a conversion factor of $0.45 \mathrm{t} \mathrm{m}^{-3}$ for coniferous raw wood and $0.59 \mathrm{t} \mathrm{m}^{-3}$ for nonconiferous raw wood (Pingoud et al., 2006). We convert the tonnes of biomass to tonnes of carbon using a factor of $0.45 \mathrm{tC} \mathrm{t}^{-1}$ (Ciais et al., 2008), though the results can be scaled up or down uniformly to give a different carbon content (e.g. $0.5 \mathrm{tC} \mathrm{t}^{-1}$ ) without changing the relative results.

\subsubsection{Crop data}

The FAO provides data on the harvest of different crops, with around 160 crops included (FAO, 2012a). This data needs to be converted from tonnes harvested to tonnes of dry matter and then from tonnes of dry matter to tonnes of carbon. We based our conversions on Ciais et al. (2008) supplemented with additional data where necessary (USDA, 2010).

\subsubsection{Livestock data}

The FAO provides data on around 15 different types of live animals (FAO, 2012a). Based on the number of live animals, we estimated the feed requirements using the models from Krausmann et al. (2008). This gives the total carbon consumed by livestock. We then used livestock conversion efficiencies (Krausmann et al., 2008) to convert the feed input into animal product output measured in terms of carbon. This approach does not necessitate differentiating between intake from grazing and that from feed.

\section{Embodied $\mathrm{CO}_{2}$ Emissions}

While the literature on embodied carbon is growing rapidly (Wiedmann et al., 2007; Wiedmann, 2009), there is not yet a broad synthesis of existing studies. One study on the Nordic countries found large variations between independent estimates, but after adjusting for inconsistent definitions and input data, it was found that the results were similar and quite robust (Peters and Solli, 2010). Our goal in this section is to synthesise existing global studies for key regions, explore the reasons for any differences between studies, and give a summary of results that are robust across studies.

\subsection{Synthesis of previous global studies}

A number of independent studies have now estimated the emissions embodied in international trade of goods and services (Ahmad and Wyckoff, 2003; Peters and Hertwich, 2008b; Nakano et al., 2009; Hertwich and Peters, 2009; Davis and Caldeira, 2010; Atkinson et al., 2011; Peters et 

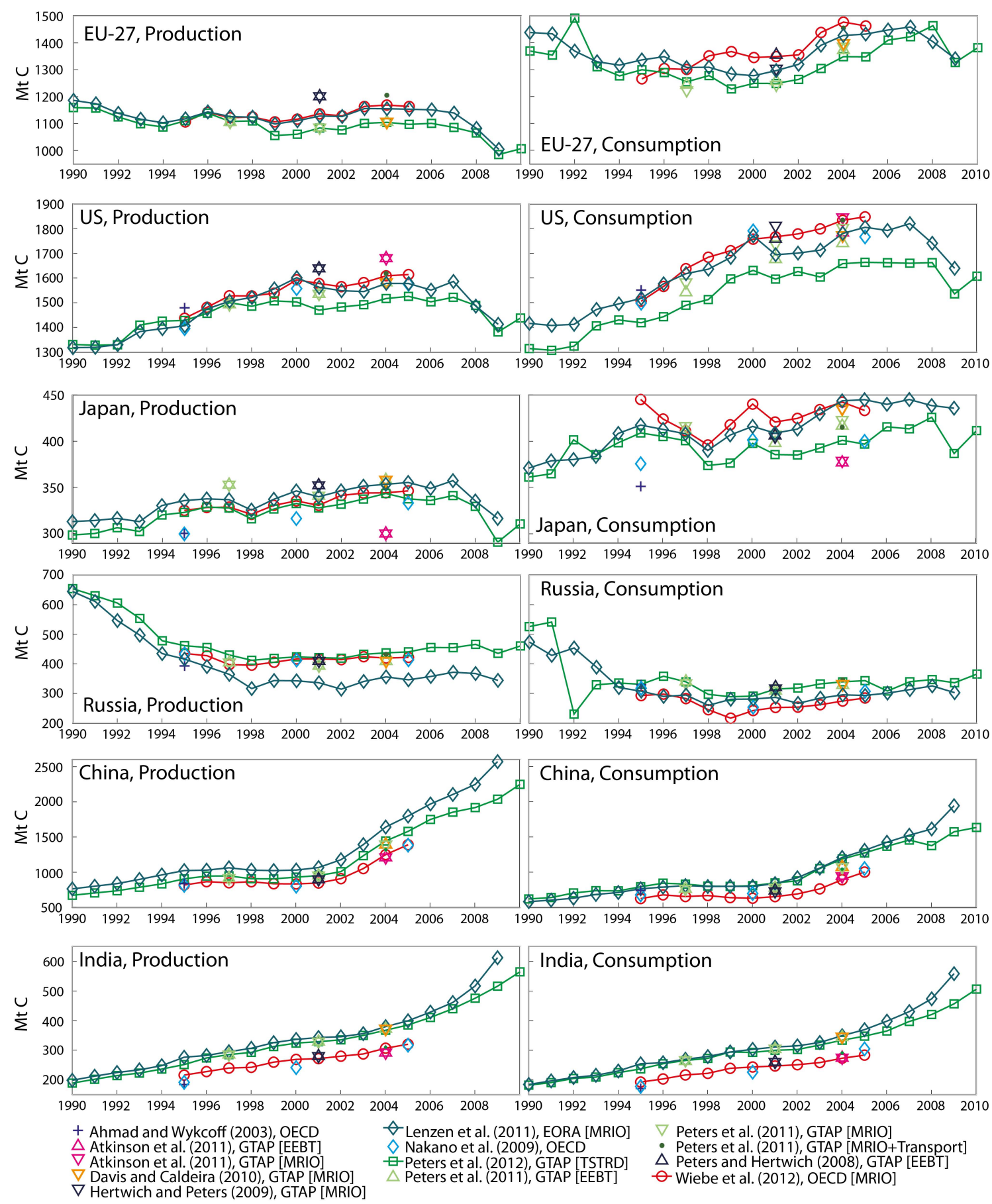

Fig. 1. Comparisons of global models of $\mathrm{CO}_{2}$ emissions embodied in traded goods and services. Each country has the same scale for production and consumption. The minimum value has not been taken as zero to highlight the differences, but relative to national totals, the differences are smaller (cf., Tables 3 and 5). Although there is some variation among studies due to differences in the underlying data and modelling methods, the patterns and trends are broadly consistent among all the studies shown.

al., 2011a, b; Wiebe et al., 2012). We restrict our comparisons to global studies using MRIO approaches, despite the existence of many country-specific studies (see the review articles; Wiedmann, 2009; Wiedmann et al., 2007). Figure 1 shows the results of the selected global studies for the
EU27, the USA, Japan, China, the Russian Federation, and India; though these studies cover up to 112 countries and regions. Table 1 shows the growth rates between the three time-series studies (Peters et al., 2012; Wiebe et al., 2012; Lenzen et al., 2012). The figure shows that the results of the 
studies are broadly consistent. Here, we focus on three differences: (1) different emissions data, (2) different definitions of consumption-based emissions, and (3) different allocation models; and we explore these differences in more detail in the following section.

Generally the studies show a correlation between the production-based estimates (left side of Fig. 1) and the consumption-based estimates (right side): if the productionbased estimates are relatively high in comparison to other studies, then the consumption-based estimates are usually also relatively high. There is also a large spread in the production-based estimates. The EEBT and MRIO methods of Peters et al. (2011b) in 1997, 2001, and 2004 and the MRIO of Davis and Caldeira (2010) in 2004 all use the CDIAC emissions data as input (Boden et al., 2011). While Peters et al. (2012) also use the CDIAC data, the use of a later update of the CDIAC data leads to the difference with Peters et al. (2011b). Peters and Hertwich (2008b), Hertwich and Peters (2009), and Peters et al. (2011a) use a modified version of the GTAP emissions data (Lee, 2008), which is different than the CDIAC estimates. Atkinson et al. (2011) use an unmodified version of the GTAP emissions data. Ahmad and Wyckoff (2003), Nakano et al. (2009), and Wiebe et al. (2012) are all based on the IEA energy or emissions data (IEA, 2011) - each study estimates different emissions - and these estimates generally differ from the CDIAC estimates (see Andres et al., 2012 for more details). Since consumption-based estimates of emissions are essentially production-based estimates adjusted for trade, differences in the production estimates will lead to differences in the consumption estimates. While the global emissions are the same for production and consumption, if the production-based estimates are high in one study for one country, then it follows that the consumption-based estimates are also likely to be high.

As already discussed, there are also different ways of defining the consumption-based emissions, and hence different consumption estimates can be derived from the same production-based emissions. Figure 1 also shows that the use of two different definitions (labelled MRIO and EEBT) is an important source of differences between studies. Peters et al. (2011b) in 1997, 2001, and 2004, Peters and Hertwich (2008b) in 2001, Hertwich and Peters (2009) in 2001, and Atkinson et al. (2011) in 2004 all present results for both the EEBT and MRIO methods; thus, even though each study starts with the same production-based estimates, the estimates for consumption are different due to different definitions of consumption. The studies of Peters et al. (2011b) and Davis and Caldeira (2010) both use the same emissions data and definitions, leading to equal estimates. Peters et al. (2011a) in 2004 uses an MRIO method extended to include international transportation in more detail, and thus leads to different estimates.

Figure 1 and Table 1 show variation in consumption-based estimates. However, the trends over time are similar among the reviewed studies (Fig. 1, Table 1). Comparisons of Fig. 1 and Table 1 show a correlation between the production- and consumption-based estimates; when the production-based estimates are high in one study, then so are the consumptionbased estimates in that study. This suggests that a large part of the variation between studies is because different studies use different production-based emission estimates. Also shown in Fig. 1 is that different definitions can also be important to explain the variations between studies. More detailed model comparisons should control for these two factors. The remaining differences between studies are due to different economic and trade data.

\subsection{Explanations of variations in results}

The variations between different studies demonstrated in the previous section do not necessarily translate into uncertainty as the different studies use different carbon emissions as input, definitions, and different attribution models. In this section, we use modifications of the GTAP-MRIO to investigate what may cause the variations between different studies. We focus on the three categories of difference discussed in the previous section: (1) differences in production-based emissions, (2) differences in definitions, and (3) variations in the economic data.

\subsubsection{Production-based emissions}

While the range of estimates of global $\mathrm{CO}_{2}$ emissions may be small, variations at the region and sector level may be larger in relative terms (Andres et al., 2012). As we have noted, such differences in production-based emissions estimates will affect the resulting consumption-based emission estimates (Fig. 1 and Table 1). In this sub-section we explore the differences in national emission estimates in more detail focusing on (a) variation in total emissions, (b) allocation of bunker fuels, (c) allocation to sectors, and (d) the propagation effects on estimates of consumption-based emissions.

\section{Variation in total emissions}

Table 3 shows estimates of carbon emissions from five different emission datasets (Table 2). We briefly summarise the five datasets here, but more details are discussed by Andres et al. (2012).

1. The Carbon Dioxide Information Analysis Center (CDIAC) data includes emissions from the combustion of fossil fuels, emissions from cement production, and emissions from gas flaring (Boden et al., 2009). The CDIAC data is based on energy statistics reported by countries to the United Nations. Bunker fuels used for international transportation are not allocated to countries, but are included in the global totals. 
Table 2. The key features included in the different carbon emission datasets used in this study.

\begin{tabular}{|c|c|c|c|c|c|}
\hline & CDIAC & UNFCCC & EDGAR & GTAP7.1 & GTAP7.1+NAMEA \\
\hline Fossil fuels & Yes & Yes & Yes & Yes & Yes \\
\hline $\begin{array}{l}\text { Cement } \\
\text { production }\end{array}$ & Yes & Yes & Yes & No & Yes \\
\hline Gas flaring & Yes & Yes & Yes & No & Yes \\
\hline $\begin{array}{l}\text { Other process } \\
\text { emissions }\end{array}$ & No & Yes & Yes & No & Mixed \\
\hline $\begin{array}{l}\text { International } \\
\text { transport (bunker } \\
\text { fuels) }\end{array}$ & $\begin{array}{l}\text { No (but included } \\
\text { in global total) }\end{array}$ & $\begin{array}{l}\text { No (reported as a } \\
\text { memo by the fuel } \\
\text { supplier) }\end{array}$ & $\begin{array}{l}\text { Yes (we allocated } \\
\text { to countries based } \\
\text { on fuel use) }\end{array}$ & $\begin{array}{l}\text { Yes (in principle, } \\
\text { though uncertain) }\end{array}$ & $\begin{array}{l}\text { Yes (in principle, } \\
\text { though varies by } \\
\text { country) }\end{array}$ \\
\hline
\end{tabular}

Table 3. Estimates of territorial-based carbon emissions (2004) from fossil fuel combustion and, in some cases, process emissions from different data sources. The first column shows the total emissions from CDIAC, and the other columns are percentage comparisons with CDIAC (positive is greater than CDIAC). The characteristics of each dataset are shown in Table 2. The CDIAC global total here does not include bunker fuels as we take the sum of the country totals excluding bunkers fuels. The "Top 10 differences globally" are sorted by the range in estimates; maximum minus minimum.

\begin{tabular}{|c|c|c|c|c|c|c|c|}
\hline & & Region & CDIAC (GtC) & UNFCCC (\%) & EDGAR $(\%)$ & GTAP7.1 $(\%)$ & GTAP7.1+NAMEA (\%) \\
\hline & & Global & 7.397 & - & 3.7 & 2.2 & 0.4 \\
\hline 1 & & United States of America & 1.517 & 9.2 & 7.3 & 13.5 & 6.7 \\
\hline 2 & $\gtrsim$ & China & 1.442 & - & -1.3 & -12.0 & -8.5 \\
\hline 3 & $\overline{0}$ & Russian Federation & 0.437 & -4.8 & 2.3 & 0.5 & -1.1 \\
\hline 4 & $\frac{0}{60}$ & Japan & 0.344 & 1.8 & 9.9 & -0.4 & 1.9 \\
\hline 5 & $\mathscr{b}$ & India & 0.367 & - & -8.7 & -17.3 & -15.7 \\
\hline 6 & $\stackrel{\mathscr{E}}{.}$ & Germany & 0.226 & 6.7 & 15.3 & 9.8 & 6.3 \\
\hline 7 & పี & Rest of Western Asia & 0.248 & - & -7.4 & 15.5 & 3.6 \\
\hline 8 & $\stackrel{0}{=}$ & United Kingdom & 0.149 & 2.7 & 16.0 & 17.2 & 15.7 \\
\hline 9 & ?̊ & Canada & 0.152 & 4.1 & 4.7 & 11.1 & 8.0 \\
\hline 10 & 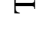 & Italy & 0.128 & 4.4 & 5.9 & 5.1 & 4.9 \\
\hline 1 & $\triangleq$ & Netherlands & 0.048 & 2.4 & 23.5 & 105.3 & 19.5 \\
\hline 2 & స్రే & Korea & 0.132 & - & 12.6 & -1.4 & -6.7 \\
\hline 3 & $\frac{0}{600}$ & Ukraine & 0.094 & -8.4 & 3.7 & -10.9 & -16.5 \\
\hline 4 & j్ & France & 0.106 & 7.5 & 16.5 & 6.0 & 5.7 \\
\hline 5 & U్d & Caribbean & 0.029 & - & -2.9 & 51.2 & 45.8 \\
\hline 6 & 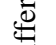 & Belgium & 0.030 & 14.0 & 29.2 & 50.0 & 14.0 \\
\hline 7 & $=$ & South Africa & 0.113 & - & -13.0 & -11.1 & -11.7 \\
\hline 8 & 으 & Nigeria & 0.026 & - & -11.1 & -46.3 & 1.6 \\
\hline & oิ & Thailand & 0.073 & - & -13.7 & -14.9 & -14.1 \\
\hline 10 & & Taiwan & 0.071 & - & 3.0 & 14.7 & 3.2 \\
\hline
\end{tabular}

2. The UNFCCC data includes emissions from the combustion of fossil fuels and process emissions such as from cement production, flaring, and other activities (IPCC, 2006). Bunker fuels are not allocated to countries, but each country shows a memo of the bunker fuels sold from that country.

3. The Emissions Database for Global Atmospheric Research (EDGAR, version 4.1) includes emissions from the combustion of fossil fuels and process emissions such as from cement production, flaring, and other activities (European Commission, 2011). The EDGAR data allocates the emissions to sectors, and in the standard EDGAR database bunker fuels are not allocated to countries. However, for the analysis that follows, we reallocated bunkers fuels to using countries based on the economic activity in the GTAP database. The EDGAR database includes forest fires, though for consistency with the other datasets, we do not include them in our analysis. 
4. The GTAP data only covers emissions from the combustion of fossil fuels Lee, 2008). The data is originally based on data from the International Energy Agency (IEA), but undergoes manipulation in construction of the GTAP database (Narayanan and Walmsley, 2008) and uses different assumptions than IEA to convert energy into $\mathrm{CO}_{2}$. Thus, the GTAP $\mathrm{CO}_{2}$ emissions will differ from the IEA $\mathrm{CO}_{2}$ dataset (IEA, 2011). In principle, bunker fuels are allocated to countries based on the use of bunker fuels by resident institutions within a country; however, in version 7.1 of the GTAP database we use, the methodology for doing this is inadequate for an accurate attribution (McDougall and van Leeuwen, 2010).

5. The GTAP+NAMEA data is a modification of the GTAP data (Peters and Hertwich, 2008b) to include the National Accounting Matrices with Environmental Accounts (NAMEAs) in the countries where they are easily available (mainly EU countries, Australia, Canada, China, Japan, and the USA), in addition to including the cement and flaring emissions from CDIAC. In the countries that use NAMEAs, bunker fuels are allocated according to resident institutions using bunker fuels.

Table 3 shows the global total from each database, in addition to the top 10 emitters and top 10 countries with the largest absolute difference in emissions. Even though the global totals are reasonably close, there is considerable variation between the country totals. These differences relate to different system boundaries, energy data, emission factors, definitions, and similar (Andres et al., 2012). At the country level, even the biggest emitters have variations of up to 10 $15 \%$. The largest absolute difference is for the Netherlands (up to $100 \%$ ), but this results from GTAP incorrectly assuming fossil fuels used as feedstock are combusted (this problem has been fixed in updated versions). Large absolute differences occur for both developed and developing countries, which suggests that it is not only data quality that is at fault, but inconsistent system boundaries, assumptions, etc. For the top 10 emitters, the average difference between the maximum and minimum values from the five datasets is $13 \%$, and the average range of all the 112 countries and regions in the database is $30 \%$. In the context of consumption-based emission estimates, it is important to note these large variations, as these differences will propagate through to give differences of similar magnitude in consumption-based estimates.

\section{Allocation of emissions from bunker fuels (international transport)}

For some countries, the method of allocating the emissions from bunker fuels to countries can have a significant effect on the emission estimates (Peters, 2008; Peters et al., 2009). The use of bunker fuels occurs in international ter- ritory, and, for the purpose of energy statistics, this energy use occurs outside of the system boundary of a nation (IEA, 2005). This definition seems to also have been applied to emissions statistics, where "[n]ational inventories include greenhouse gas emissions and removals taking place within national territory andoffshore areas over which the country has jurisdiction" (IPCC, 2006). A consequence of this is that countries are not allocated emissions from the use of bunker fuels (international transport); however, countries do report the sales of bunker fuels as a memo in UNFCCC statistics. To be consistent with the System of National Accounts, emissions from international transport should be allocated to the country where the operator of the vessel is resident (Peters and Hertwich, 2008a; Peters, 2008; Peters et al., 2009; European Commission, 2009), corresponding to the user of the bunker fuel (and independent of the ship's flag and owner). Emissions statistics that allocate emissions consistent with the System of National Accounts are often called National Accounting Matrices with Environmental Extensions (NAMEAs) (Pedersen and de Haan, 2006; European Commission, 2009), though this terminology is not applied uniformly.

While estimates of bunker fuel emissions allocated to selling country are available, data on residency of using vessels are often not reported (Peters et al., 2009). Many European countries, however, report the necessary data to Eurostat to make the "bridge" table between emissions allocated to the national accounts and the emissions submitted to the UNFCCC. Table 4 demonstrates the differences between bunker fuel sales (memo in the UNFCCC reporting) and usage (as required for NAMEAs) for the 17 European countries reporting the data. For these countries, the sales of bunker fuels represent $8.1 \%$ of the UNFCCC inventory, while use of bunker fuels is slightly lower at $7.7 \%$, suggesting that, across Europe, bunker fuel sales roughly balance with bunker fuel usage. However, there are large variations between countries. The Netherlands, for example, has very high bunker fuel sales (34\% of UNFCCC inventory) and relatively small use $(11 \%)$. Denmark, in contrast, has very large bunker fuel use (almost equal to the total emissions reported to the UNFCCC) but relatively small bunker fuel sales (11\%).

Residency adjustments are required for land transport and tourist activities. Adjusting for land transport is particularly problematic for small countries, such as Luxembourg, where there may be significant disparities between location of purchases of petrol and location of use for driving. The correction for tourists requires removing the activities of foreign tourists (which become exports: sales to other countries), and adding the activities of tourists abroad (which become imports: purchases from other countries). 
Table 4. The "bridge" table connecting the UNFCCC and NAMEA inventories for reporting European countries in 2007. By convention, the UNFCCC memo on bunker fuels is recorded but not included in national totals. According to the NAMEA (economic accounting), allocation should be based on resident institutes, and thus adjustments must be made primarily for bunker fuel use when converting from a UNFCCC inventory to a NAMEA. The last set of rows shows the percentages relative to the UNFCCC totals. In most cases the NAMEAs are higher as they include international transport, while the UNFCCC inventories do not.

\begin{tabular}{|c|c|c|c|c|c|c|c|c|c|c|c|c|c|c|c|c|c|c|}
\hline Values for 2007 (MtC, \%) & 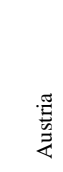 & 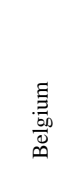 & 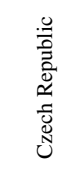 & 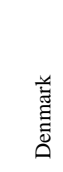 & 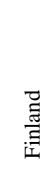 & 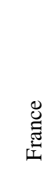 & 胥 & 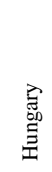 & 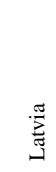 & 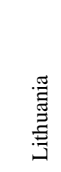 & 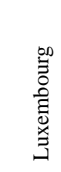 & 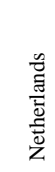 & 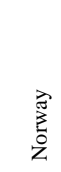 & $\begin{array}{l}\overrightarrow{\text { ज्ञ }} \\
\text { 잉 }\end{array}$ & 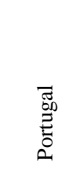 & 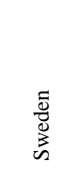 & 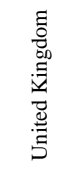 & 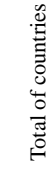 \\
\hline Emissions reported to the UNFCCC (1) & 20 & 31 & 34 & 15 & 18 & 106 & 228 & 16 & 2 & 4 & 3 & 50 & 12 & 89 & 17 & 14 & 149 & 810 \\
\hline UNFCCC Memo: Bunker Fuels ( 2 , not in any totals) & 1 & 9 & 0 & 2 & 1 & 7 & 10 & 0 & 0 & 0 & 0 & 17 & 1 & 1 & 1 & 3 & 12 & 65 \\
\hline Activities by national residents abroad (3) & 0 & 3 & 0 & 14 & 2 & 3 & 15 & 1 & 0 & 1 & 0 & 7 & 4 & 2 & 1 & 3 & 16 & 72 \\
\hline Activities by non-residents in the territory (4) & 2 & 0 & 1 & 0 & 0 & 0 & 2 & 0 & 0 & 0 & 1 & 2 & 0 & 0 & 1 & 0 & 0 & 9 \\
\hline Other adjustments and statistical discrepancy (5) & -1 & 0 & 1 & 0 & 0 & -1 & 0 & 0 & 0 & 0 & 0 & 0 & 0 & 0 & -1 & 0 & 1 & -1 \\
\hline Emissions for the NAMEA $(5)=(1)+(3)-(4)-(5)$ & 19 & 34 & 33 & 29 & 20 & 109 & 241 & 16 & 3 & 5 & 2 & 56 & 16 & 91 & 18 & 17 & 165 & 874 \\
\hline UNFCCC Memo: Bunker Fuels (2)/(1)\% & 3.0 & 30.2 & 0.8 & 11.2 & 4.8 & 7.0 & 4.2 & 1.2 & 9.3 & 3.7 & 11.5 & 33.9 & 7.2 & 0.6 & 6.8 & 18.3 & 8.3 & 8.1 \\
\hline Net activities by residents $(3-4) /(1) \%$ & -8.5 & 8.1 & -0.9 & 96.8 & 9.2 & 2.6 & 5.8 & 3.5 & 14.4 & 14.1 & -28 & 10.5 & 31.1 & 2.2 & -2.0 & 18.4 & 10.9 & 7.7 \\
\hline Emissions for the NAMEA (5)/(1) \% & 94 & 109 & 97 & 197 & 109 & 104 & 106 & 102 & 114 & 114 & 72 & 111 & 131 & 102 & 104 & 119 & 110 & 108 \\
\hline
\end{tabular}

\section{Allocation of emissions to sectors}

For economic analysis, or attribution studies as in this article, emissions are distributed to the sectors where they occur. For our analysis it is necessary to have detail for each of the 57 sectors in each region, but it is not uncommon to differentiate around 500 sectors in some individual countries (such as the USA and Japan). Uncertainty increases as emissions are disaggregated to sectors, and consequently the differences between datasets increase. In this section we compare the sector differences for direct emissions between three datasets to indicate the possible implications they may have on consumption-based emissions inventories.

Figure 2 shows the absolute difference between the standard GTAP sector emissions and the updated version, GTAP+NAMEA. The relative differences are larger but often occur in sectors with small emissions, and hence do not have a large impact on results. Most of the differences occur in the countries that are updated in GTAP+NAMEA (Australia, New Zealand, Canada, China, Japan, the USA, and the EU27). However, differences are also apparent in mineral products (cement), oil and gas (flaring), and refineries (downward adjustment of incorrectly combusted feedstocks in the original GTAP data). The differences can be quite large, in excess of $100 \mathrm{MtC}$ in either direction. The largest differences occur due to the treatment of bunker fuels (air and sea transport), land transport, and electricity.

Figure 3 shows the analogous results comparing the standard GTAP emissions with the EDGAR dataset. The EDGAR dataset is initially allocated to different sectors than GTAP, and thus we remapped the EDGAR sector emissions to the GTAP classification. This step may introduce additional errors as the mapping is not one-to-one. Since the EDGAR and GTAP database are independent, the differences are more widespread. The largest differences occur in the transport sectors (including bunker fuels), electricity, and the energy intensive sectors such as metal manufacturing and cement.

Thus, while emissions may vary at the country level, there may be more significant and important differences at the sector level. The differences in these datasets will propagate through to the estimates of the consumption-based emissions.

\subsubsection{Consumption-based emission estimates}

The previous section demonstrated that there can be significant differences between emission datasets and these occur at three levels: (1) aggregated emissions, (2) treatment of bunker fuels, and (3) allocation of emissions to sectors. For most countries, the production-based emissions account for the largest share of the consumption-based emission inventories. Thus, the use of different production-based emission estimates may lead to a perception that the methodology to construct consumption-based emission estimates is highly uncertain. This section quantifies these differences for five emission datasets.

Table 5 shows the consumption-based emission estimates using five different production-based emission inventories. The variation in consumption-based emission estimates is comparable with the variation in production-based estimates. The average range of the estimates for the top 10 is $11 \%$, slightly less than for production estimates $(13 \%)$. The average range of all 112 countries and regions in the database is $16 \%$, less than the average for production (30\%). Interestingly, the spread in production-based emission inventories is generally higher than the spread in the consumptionbased inventories (Fig. 4); 90 of the 112 countries and regions have a more accurate consumption-based inventory. This counter-intuitive result is probably since (1) the range 


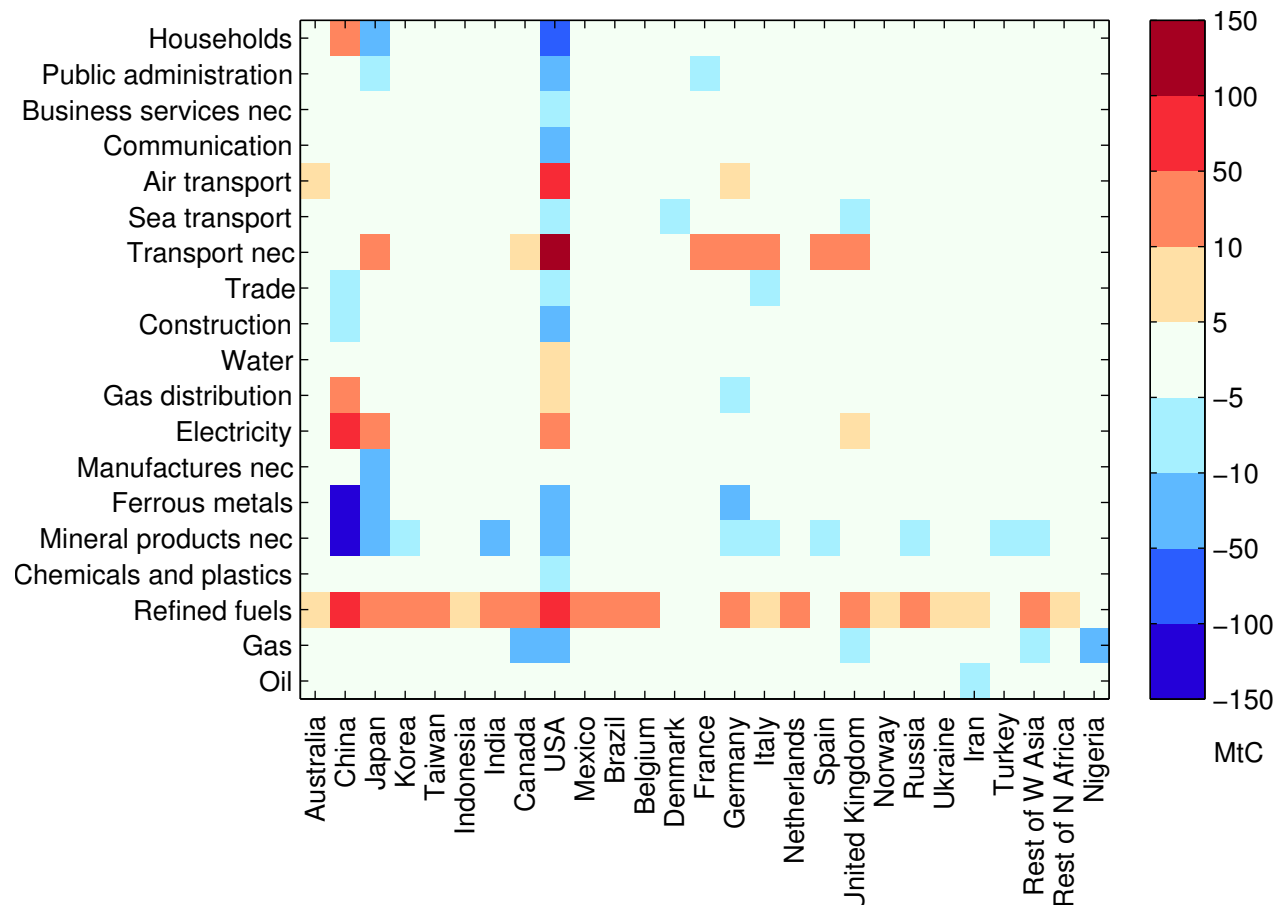

Fig. 2. The difference between the default GTAP $\mathrm{CO}_{2}$ emission dataset and a version which includes (1) national statistics when available (Australia, NZ, China, Japan, USA, Canada, EU27), (2) cement and flaring emissions, and (3) adjustments to feedstocks used in the refinery sector. The differences are shown by sector and region and are in MtC for 2004. Positive values indicate that "GTAP" is larger. We only show the sector and region combinations where the difference is greater than $5 \mathrm{MtC}$.

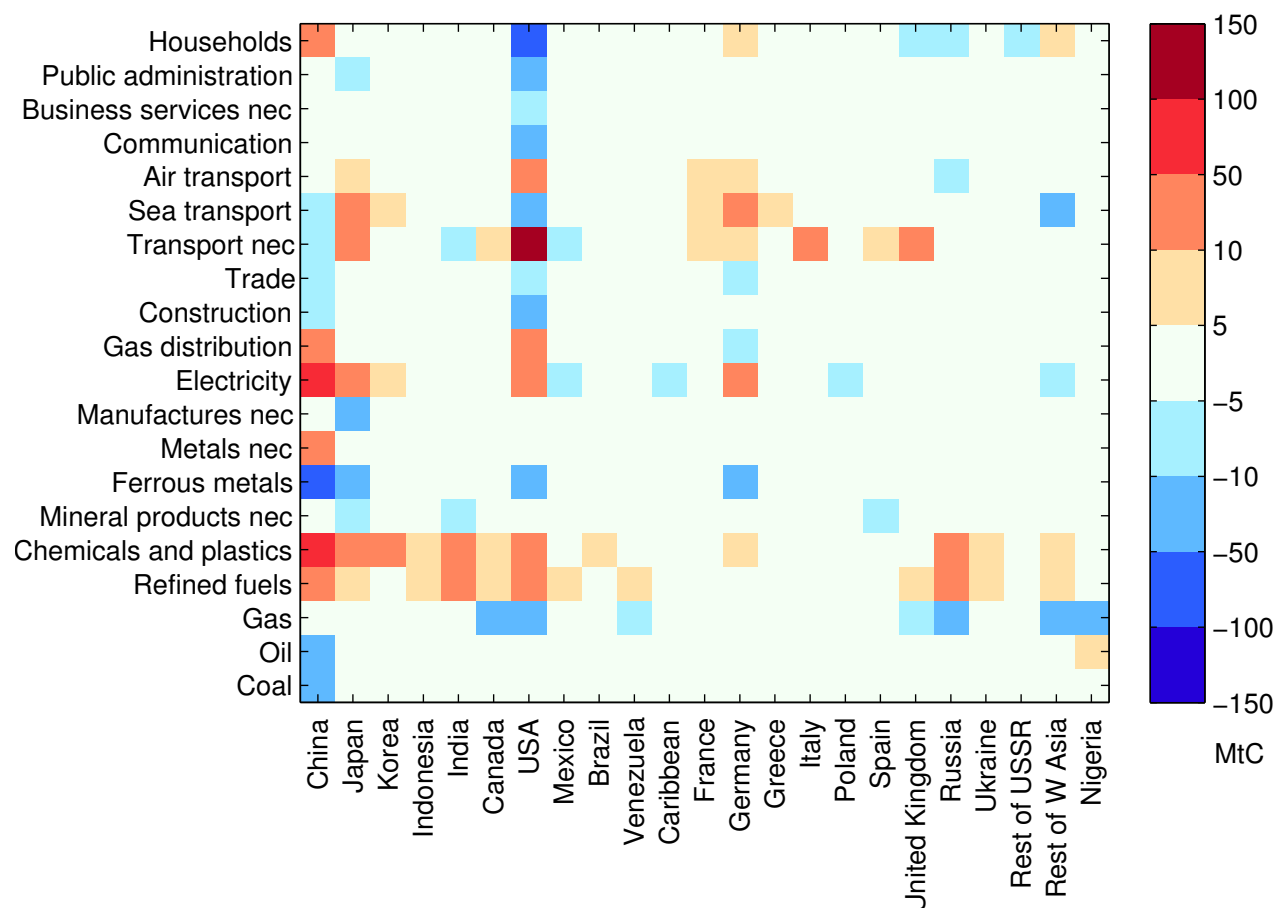

Fig. 3. The difference between the default GTAP $\mathrm{CO}_{2}$ emission dataset and the EDGAR dataset with the sectors reallocated to the GTAP sectors. The differences are shown by sector and region and are in MtC for 2004. Positive values indicate that "GTAP" is larger. We only show the sector and region combinations where the difference is greater than $5 \mathrm{MtC}$. 
Table 5. Estimates of consumption-based inventories (2004) using the emissions data from Table 2 (see caption and text). The first column shows the total emissions from CDIAC, and the other columns are percentage comparisons with CDIAC (positive is greater than CDIAC). The percentage differences are around the same order as for production, suggesting that the dataset used for the production-based emissions is important in determining the variation in consumption-based emissions between studies. The "Top 10 differences globally" are sorted by the range in estimates; maximum minus minimum.

\begin{tabular}{|c|c|c|c|c|c|c|c|}
\hline & & Region & CDIAC (GtC) & $\mathrm{UNFCCC}(\%)$ & EDGAR (\%) & GTAP71 (\%) & GTAP71+NAMEA (\%) \\
\hline & & Global & 7.397 & & 3.7 & 2.2 & 0.4 \\
\hline 1 & & United States of America & 1.730 & 7.6 & 5.4 & 9.5 & 5.1 \\
\hline 2 & $\gtrsim$ & China & 1.134 & & -1.0 & -10.9 & -7.9 \\
\hline 3 & $\overline{\bar{\pi}}$ & Japan & 0.409 & 1.7 & 9.0 & 2.5 & 0.6 \\
\hline 4 & $\frac{0}{0 D}$ & Russian Federation & 0.353 & -4.4 & 0.3 & -0.4 & -1.1 \\
\hline 5 & $\tilde{b}$ & Germany & 0.277 & 4.9 & 13.6 & 11.5 & 4.2 \\
\hline 6 & $\stackrel{\mathscr{\Xi}}{:}$ & India & 0.338 & & -7.8 & -15.9 & -14.4 \\
\hline 7 & हี & United Kingdom & 0.208 & 2.5 & 13.7 & 14.6 & 9.0 \\
\hline 8 & 으 & Rest of Western Asia & 0.225 & & -4.6 & 6.9 & 2.1 \\
\hline 9 & के & Italy & 0.164 & 3.5 & 7.0 & 4.1 & 3.3 \\
\hline 10 & $F$ & France & 0.151 & 5.3 & 11.6 & 6.1 & 4.1 \\
\hline 1 & $\gtrsim$ & Canada & 0.139 & 4.2 & 9.8 & 12.8 & 6.0 \\
\hline 2 & กี & Netherlands & 0.059 & 2.3 & 13.8 & 28.9 & 9.8 \\
\hline 3 & $\frac{\overline{0}}{000}$ & Korea & 0.134 & & 6.7 & -2.3 & -5.2 \\
\hline 4 & s & Caribbean & 0.032 & & -0.3 & 35.7 & 31.2 \\
\hline 5 & 巳一 & Australia & 0.091 & 6.8 & 12.4 & 7.0 & 4.7 \\
\hline 6 & 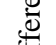 & Brazil & 0.084 & & 8.7 & 2.0 & -3.7 \\
\hline 7 & 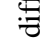 & South Africa & 0.075 & & -12.7 & -9.9 & -10.4 \\
\hline 8 & 으 & Norway & 0.016 & 2.6 & 59.5 & 19.5 & 15.1 \\
\hline & के & Belgium & 0.045 & 6.7 & 20.2 & 20.9 & 6.2 \\
\hline 10 & H & Ukraine & 0.064 & -7.4 & -8.4 & -11.0 & -14.1 \\
\hline
\end{tabular}

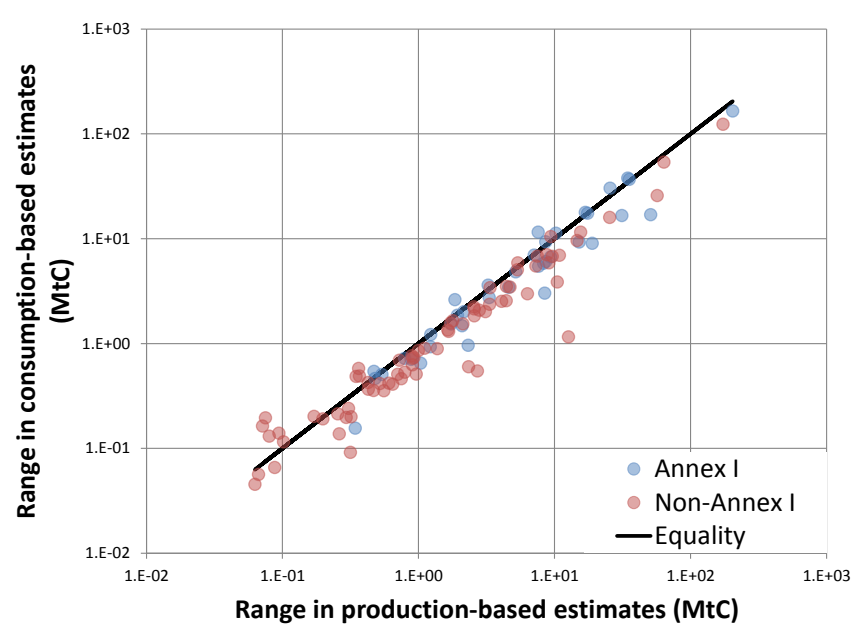

Fig. 4. The range in the production- and consumption-based estimates (2004). The straight line is equal ranges $(y=x)$. The consumption-based estimates are, counter-intuitively, more accurate than the production-based estimates.

of the consumption-based estimates only includes a part of the production-based with the remainder due to imports, and (2) most exports come from large countries where there is a smaller spread in production-based estimates. The coun- tries with the largest spread in production-based estimates are importing from countries with a lower range in productionbased estimates, and this thereby reduces the overall variation in consumption-based estimates. As an extreme example, if a country had a $10 \%$ spread in the production-based estimates and imported from countries with a $5 \%$ spread, then it would be expected that the spread in the consumptionbased estimates would be less than $10 \%$ but greater than $5 \%$. Likewise, if the import partners had a spread of $15 \%$, then it would be expected that the consumption-based estimate would have a spread of between $10-15 \%$. These examples are based purely on the variation in the productionbased estimates, and do not consider additional uncertainties at the sector level which would need a more detailed analysis (e.g. Lenzen et al., 2010; Lenzen, 2011). Despite this, the spreads in production- and consumption-based estimates are of comparable magnitude. Thus, if two studies use an emission dataset where a country has a $10 \%$ spread in productionbased emissions, then it would be expected that the spread in the consumption-based emissions would be around $10 \%$ too. This result is also shown in a more qualitative nature in Fig. 1.

Figure 5 shows the spread in the difference in consumption-based and production-based estimates for the 20 countries with the largest differences; this is similar 


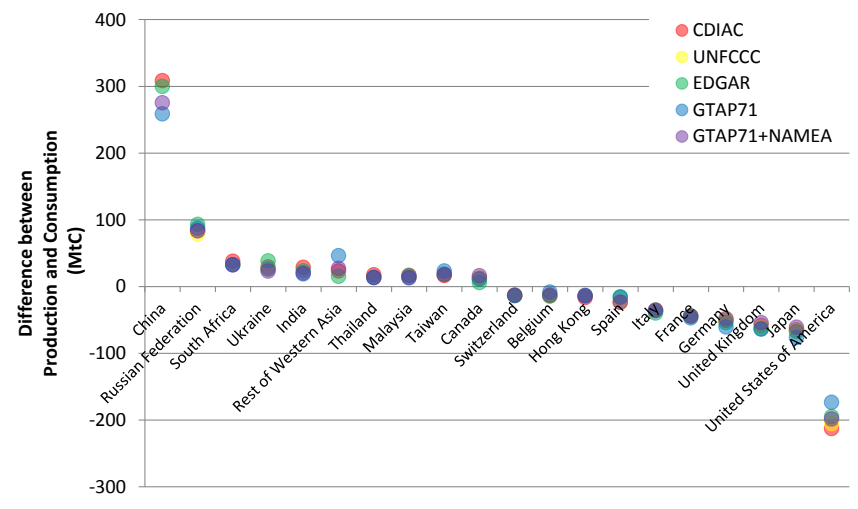

Fig. 5. The difference between Production and Consumption for the 20 countries with the largest differences for the CDIAC database (2004). The results are shown for all the databases. Note that UNFCCC only has values in Annex I countries.

to a "trade balance" in embodied emissions (Peters, 2008; Kanemoto et al., 2012). The uncertainty of both the production and consumption results is included here, though they may tend to cancel, leading to a relatively robust trade balance. The figure shows that the trade imbalance of the selected countries is robust across different datasets. The largest spread is for "Rest of Western Asia", which represents a region without specific data (derived from other countries' data); hence, greater uncertainty is expected. The largest trade imbalances are for China and the USA. Even though the figure represents the 20 largest trade imbalances, some small countries that are highly dependent on trade appear in the results, for example Taiwan, Switzerland, Belgium, and Hong Kong. The normalised trade balance (relative to the production-based emissions) is relatively stable for the top 20 countries, excluding the small countries. For smaller countries, in general, the spread in estimates is much larger, and can change sign (results not shown). Overall, the trade balances are robust for the largest emitters, independent of the dataset used.

\subsubsection{Differences due to the definition of consumption-based emissions}

There are different ways to define the "carbon footprint" or "consumption-based emissions" (Wiedmann and Minx, 2008; Peters, 2008, 2010a; Kanemoto et al., 2012). Table 6 shows the top 10 emitters, and top 10 relative differences, in terms of consumption using two different definitions (Peters et al., 2011a). In the top 10, the differences can be as large as $25 \%$ (China). The mean relative difference for the top 10 countries is $17 \%$. The largest relative differences are around $50 \%$, and occur for either small countries or countries with poor data. It is not possible to know the magnitude or direction of the difference without performing specific calculations (Su and Ang, 2011; Kanemoto et al., 2012). Differences are generally larger for small and trade-exposed countries such as Singapore, Taiwan, Malaysia, and Belgium (Peters et al., 2011a). The average difference for the 112 countries and regions in the database is $21 \%$, signifying that definitions could be a key reason for differences in results. While we have only compared two main definitions, other studies can use other different and less standard definitions (cf. Peters and Solli, 2010). These results clearly show that to ensure robust comparisons between studies, it is important to control for different definitions.

\subsubsection{Variations in economic data}

We are not aware of a detailed comparison of the differences between MRIOTs, but we can get an indication using a comparison between GTAP7.0 and GTAP7.1. The main differences between these two versions are an update of all EU27 countries and updates of the macroeconomic data.

Table 7 shows the top 10 emitters and relative differences between the two versions of the GTAP7 database. The average difference over all countries was $1 \%$, the average for the largest 10 emitters was $2 \%$, but the maximum difference was $11 \%$ (Bulgaria). The average difference for the top 10 relative differences was $5 \%$. Of the 20 countries listed, 14 are from the EU27, which is also where most of the differences are between the GTAP7.0 and GTAP7.1 databases (around $5 \%$ on average). This suggests that the changes in the EU27 data primarily affected the carbon footprint of the EU27 countries, and on the order of $5 \%$. However, there were some surprises, such as the large absolute differences in the "Rest of Western Asia", China, Japan, and the USA. These are presumably due to changes in trade with the EU27 and updated macro data. At least for the MRIOTs we compare here, the differences between MRIOTs are less than for different emissions data and the consumption-based emission definition. Even if comparing the EU27 countries only, the differences due to the emissions data and the consumptionbased emission definition are still larger.

\subsubsection{Parametric uncertainty}

In the previous sections we compared results by changing one factor at a time. It is also possible to perform a more comprehensive uncertainty analysis using Monte Carlo analysis (Bullard and Sebald, 1988). In general, when applied to consumption-based emission calculations, these studies generally find that the uncertainty is only slightly larger than the uncertainty in production-based estimates (Yamakawa and Peters, 2009; Lenzen et al., 2010; Wilting, 2012). However, these results have to be put into perspective. It is generally difficult to find uncertainty estimates for economic and trade data, thus it is often assumed that small transactions have a larger relative error than large transactions (Lenzen et al., 2010). It is also assumed that the uncertainty of the transactions are uncorrelated, which is not the case; for example, if coal consumption is higher than expected, then gas 
Table 6. The differences resulting from using different definitions for consumption-based inventories (2004), showing the top 10 emitters in terms of consumption. The differences are measured relative to the MRIO definition.

\begin{tabular}{|c|c|c|c|c|c|c|}
\hline & & Region & EEBT (MtC) & MRIO (MtC) & Difference (MtC) & Difference $(\%)$ \\
\hline 1 & & United States of America & 1619 & 1818 & -198.8 & -10.9 \\
\hline 2 & $\triangleq$ & China & 1319 & 1044 & 275.3 & 26.4 \\
\hline 3 & సี & Russian Federation & 432 & 349 & 83.0 & 23.8 \\
\hline 4 & $\frac{0}{000}$ & Japan & 350 & 411 & -61.1 & -14.8 \\
\hline 5 & $\infty$ & India & 310 & 290 & 20.0 & 6.9 \\
\hline 6 & $\stackrel{\mathscr{E}}{=}$ & Germany & 240 & 288 & -48.3 & -16.8 \\
\hline 7 & हี & Rest of Western Asia & 257 & 229 & 27.2 & 11.9 \\
\hline 8 & $\stackrel{0}{=}$ & United Kingdom & 172 & 227 & -54.3 & -24.0 \\
\hline 9 & ô & Canada & 164 & 148 & 16.0 & 10.9 \\
\hline 10 & - & Italy & 135 & 170 & -35.2 & -20.7 \\
\hline 1 & $\triangleq$ & Nigeria & 27 & 17 & 10.0 & 59.5 \\
\hline 2 & $\overline{\bar{\pi}}$ & Malawi & 0.2 & 0.5 & -0.2 & -53.3 \\
\hline 3 & $\frac{0}{000}$ & Malaysia & 40 & 26 & 13.4 & 51.6 \\
\hline 4 & 0 & Switzerland & 14 & 27 & -12.9 & -48.3 \\
\hline 5 & Ẽ & South Africa & 100 & 67 & 32.3 & 47.9 \\
\hline 6 & $\stackrel{\Xi}{\mathscr{E}}$ & Latvia & 2.1 & 4.0 & -1.9 & -47.9 \\
\hline 7 & $=$ & Hong Kong & 16 & 29 & -13.5 & -46.0 \\
\hline 8 & 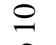 & Singapore & 12 & 21 & -8.8 & -42.6 \\
\hline & ô & Ukraine & 78 & 55 & 22.9 & 41.5 \\
\hline 10 & & Mauritius & 0.7 & 1.1 & -0.5 & -41.4 \\
\hline
\end{tabular}

Table 7. The top 10 emitters and relative differences using the GTAP7.0 and GTAP7.1 databases with the same (GTAP7.0) emission dataset (2004). The main differences are for the EU27 countries, which is where the economic data is most different.

\begin{tabular}{|c|c|c|c|c|c|c|}
\hline & & Region & GTAP7.0 (MtC) & GTAP7.1 (MtC) & Difference (MtC) & Difference $(\%)$ \\
\hline 1 & & United States of America & 1828 & 1818 & 9.5 & 0.5 \\
\hline 2 & $\triangleq$ & China & 1019 & 1044 & -24.9 & -2.4 \\
\hline 3 & స్ & Japan & 416 & 411 & 4.5 & 1.1 \\
\hline 4 & $\frac{0}{60}$ & Russian Federation & 349 & 349 & -0.1 & 0.0 \\
\hline 5 & $\tilde{\omega}$ & India & 291 & 290 & 1.3 & 0.4 \\
\hline 6 & $\stackrel{\mathscr{E}}{\Xi}$ & Germany & 293 & 288 & 4.9 & 1.7 \\
\hline 7 & ฮี & Rest of Western Asia & 218 & 229 & -11.4 & -5.0 \\
\hline 8 & $\stackrel{0}{=}$ & United Kingdom & 231 & 227 & 4.3 & 1.9 \\
\hline 9 & ? & Italy & 163 & 170 & -6.3 & -3.7 \\
\hline 10 & 5 & France & 160 & 157 & 3.7 & 2.3 \\
\hline 1 & $\gtrsim$ & Bulgaria & 13 & 11 & 1.3 & 11.2 \\
\hline 2 & స్ & Finland & 20.2 & 21.6 & -1.4 & -6.4 \\
\hline 3 & $\frac{0}{600}$ & Sweden & 27 & 26 & 1.6 & 6.2 \\
\hline 4 & $\ddot{s}$ & Netherlands & 68 & 64 & 3.7 & 5.8 \\
\hline 5 & ల్ & Slovenia & 5 & 5 & 0.3 & 5.4 \\
\hline 6 & 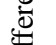 & Belgium & 45.4 & 47.3 & -1.9 & -3.9 \\
\hline 7 & $\because$ & Austria & 30 & 29 & 0.9 & 3.1 \\
\hline 8 & $\stackrel{0}{=}$ & Slovakia & 10 & 10 & 0.3 & 2.9 \\
\hline & है & Romania & 27 & 28 & -0.8 & -2.8 \\
\hline 10 & & Ireland & 17.1 & 17.4 & -0.4 & -2.1 \\
\hline
\end{tabular}




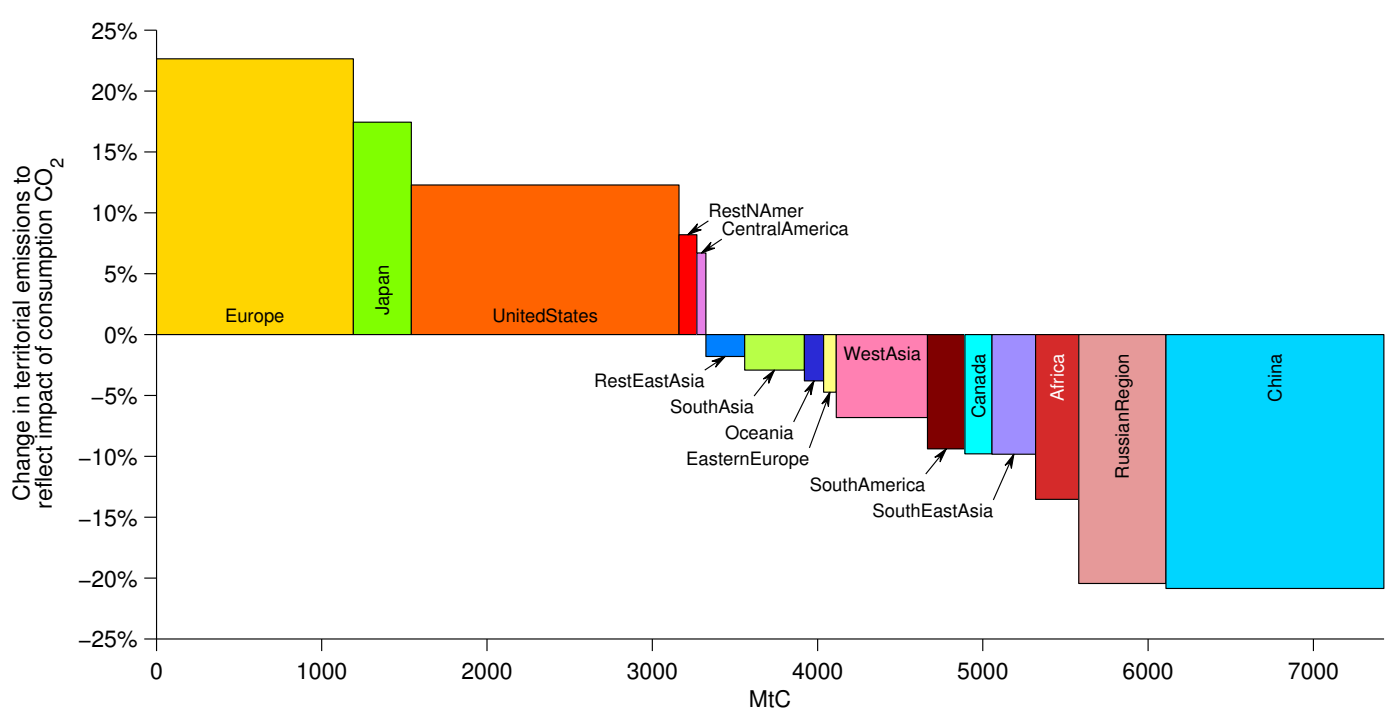

Fig. 6. The change in production-based $\mathrm{CO}_{2}$ emissions when adjusted to a consumption basis (2004). The horizontal axis shows production emissions, while the vertical axis shows the relative change. This figure disaggregates key regions from the RECCAP region set. In particular, this highlights the significant difference between Japan and China, both in the East Asia region.

consumption may be lower. A typical MRIOA involves an infinite number of additions and subtractions (achieved by matrix inversion), and differences based on uncorrelated errors tend to cancel (Peters, 2007). Thus, for these results to be confirmed, more detailed uncertainty data, including correlations, is needed. In addition, since it is also found that the most uncertain data are usually small and have only little impact on the results (Lenzen et al., 2010; Jensen, 1980; Jensen and West, 1980), then it may be more effective to perform targeted sensitivity analysis (Wilting, 2012). Nevertheless, the available literature suggests the variation in economic data may not be that important for consumption-based estimates at the national level, but differences may persist at the sector level (Lenzen et al., 2010; Lenzen, 2011; Wilting, 2012).

\subsubsection{Summary of the differences in consumption-based estimates}

Table 5, Table 6, and Table 7 show the differences in consumption-based estimates when only one factor is varied at a time. In Table 5, we show the effect of varying production-based emissions data. In Table 6, we show the effect of using different definitions of the consumptionbased emissions. In Table 7, we demonstrate the effect of modest variations in the economic input data. The resulting consumption-based estimates were affected most by different production-based estimates, affected less by different definitions, and affected least of all different economic and trade data. However, it should be emphasised that the effect of differences in the economic and trade data is likely to be underestimated because most elements of the core dataset (economic and trade data) were the same.
Figure 1 shows the variation between different emission estimates between published studies, but based on results in this section, it is expected that if these studies used the same production-based emission data and the same definitions, then the results would converge. This suggests that the model spread for consumption-based estimates may be less than presently presumed. This finding is confirmed by Monte Carlo analyses which find that consumption-based emission estimates are only slightly more uncertain than productionbased estimates. However, the Monte Carlo estimates assume uncorrelated errors. To confirm the findings reported here, more detailed model intercomparisons, sensitivity analyses, and Monte Carlo analyses are needed from a broad range of independent models.

\subsection{Overview of key results}

The previous two sections have presented the reasons for variation between consumption-based estimates, but not much has been said about the results. In this section, we summarise some of the main conclusions using the GTAP-MRIO version 7.1 with 2004 data.

Figure 1 and Table 1 show that a significant fraction of emissions produced in emerging markets like China and India are embodied in exported goods to consumers in developed regions like the USA, Japan and the EU27. Figure 6 shows the difference between production and consumption emissions for the RECCAP regions with Japan, USA, Canada, and China additionally disaggregated. Most developed countries are importers of embodied $\mathrm{CO}_{2}$ emissions, with the exception of some exporters such as Canada and Oceania (mainly Australia). We have separated Japan and China from East Asia as the exports and imports tend to 


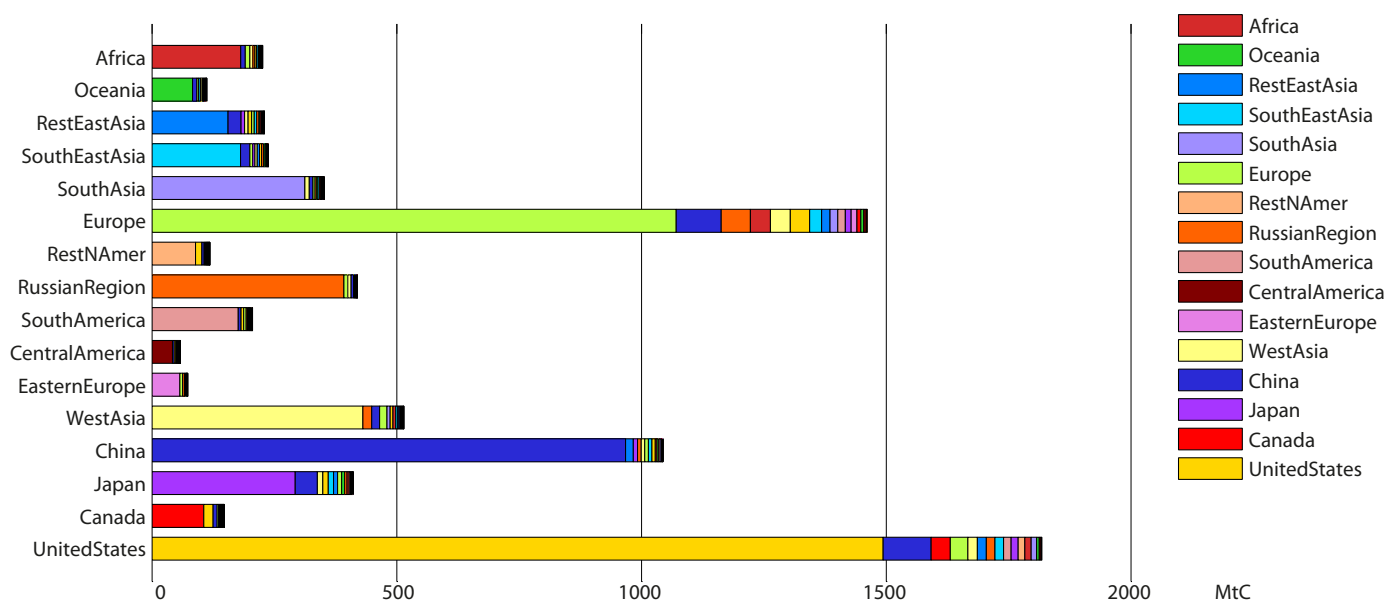

Fig. 7. Consumption-based emissions by region, disaggregating the regions where the emissions occur after adjusting for international trade (2004). Developed regions have a higher proportion of consumption emissions from other regions, and the largest single contributor to imported emissions in developed regions is China.
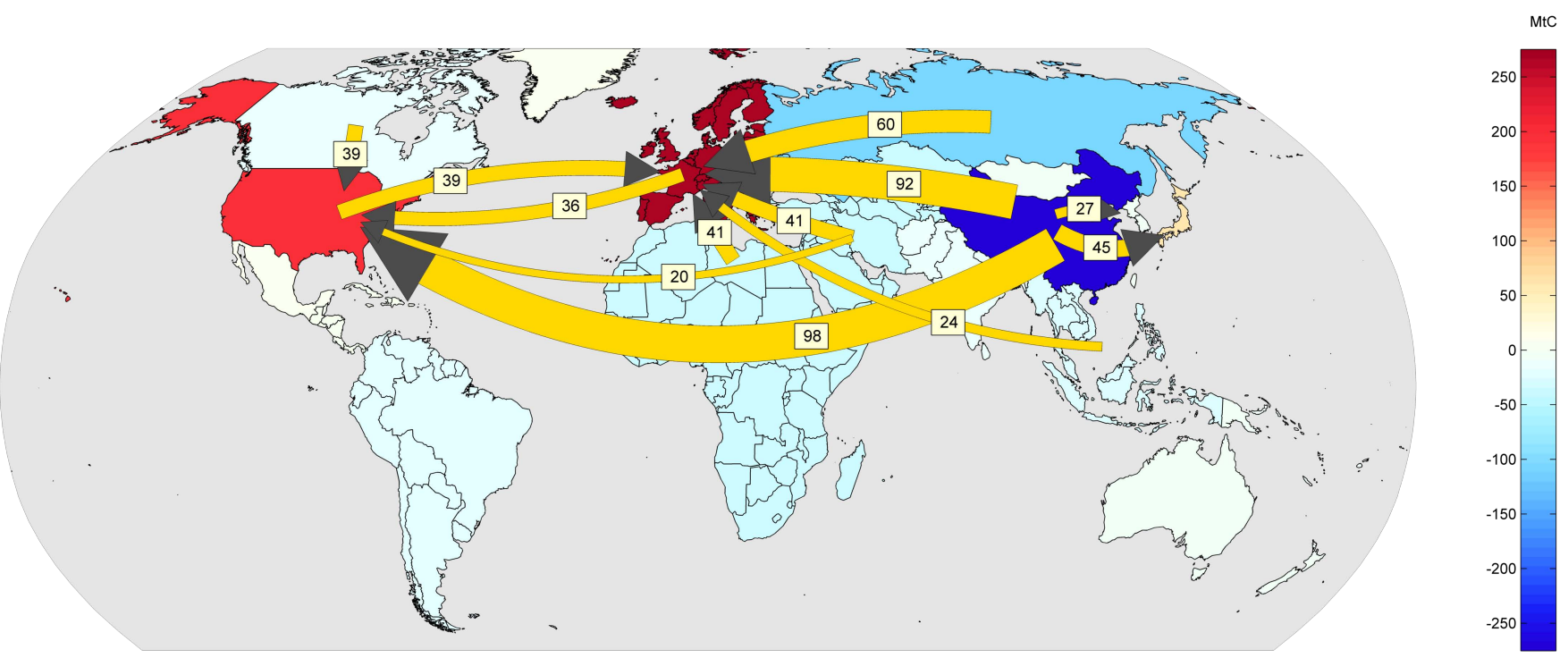

Fig. 8. The 12 largest inter-regional flows of carbon embodied in trade, from origin of emissions to the region of final consumption, with key regions disaggregated (2004). The largest single inter-regional flow is from China to USA (98 MtC). These 12 flows account for $40 \%$ of all inter-regional flows using this grouping.

cancel each other losing some policy-relevant information; we do the same for the USA, Canada, and North America. While Europe imports $23 \%$ of its production-based emissions, there is a lot of variation within European countries; for example, Latvia has a net import of $92 \%$ and the Czech Republic has a net export of $19 \%$, but 21 of the 27 EU countries are net importers of emissions.

Figure 7 shows the consumption-based emission estimates in each RECCAP region and where the emissions occur. At the regional level, most of the emissions occur within the region, though for some individual countries most of the consumption-based emissions can occur outside of the country (e.g. Singapore $67 \%$, Switzerland $60 \%$, and Swe- den $55 \%$ ). China is a particularly important country with a sizeable contribution to most other countries' consumptionbased emission estimates. Figure 8 shows the 12 largest trade flows between the regions, highlighting the role of China and Russia as important exporters to both Europe and the USA. There are also large flows between Europe and the USA, but these tend to cancel each other.

Recent studies have found that the size of the emission transfers are growing rapidly over time, much faster than many other macroeconomic variables (Nakano et al., 2009; Peters et al., 2011b; Wiebe et al., 2012; Lenzen et al., 2012). Table 1 confirms that, in general, consumptionbased emissions in developed countries are growing faster 
Table 8. The 2004 fossil fuel carbon extracted in each region (extraction), the amount and share exported, the consumption of fossil fuel carbon (equal to the territorial-based emissions) amount and share imported, and the difference between extraction and production (and exports and imports). Exports and imports only represent the trade between the RECCAP regions, and do not include the trade between countries within a region (e.g. Finland and Sweden). The shares are always in terms of extraction.

\begin{tabular}{lrrr|rrr|rr}
\hline & \multicolumn{3}{c}{ Extraction } & \multicolumn{2}{c|}{ Production } & \multicolumn{2}{c}{ Balance } \\
\cline { 2 - 8 } Region & $\begin{array}{l}\text { Extraction } \\
(\mathrm{MtC})\end{array}$ & $\begin{array}{r}\text { Exports } \\
(\mathrm{MtC})\end{array}$ & $\begin{array}{r}\text { Share } \\
(\%)\end{array}$ & $\begin{array}{r}\text { Production } \\
(\mathrm{MtC})\end{array}$ & $\begin{array}{r}\text { Imports } \\
(\mathrm{MtC})\end{array}$ & $\begin{array}{r}\text { Share } \\
(\%)\end{array}$ & $\begin{array}{r}\text { Balance } \\
(\mathrm{MtC})\end{array}$ & $\begin{array}{r}\text { Share } \\
(\%)\end{array}$ \\
\hline Africa & 566 & 362 & 64 & 240 & 36 & 6 & 325 & 58 \\
Oceania & 245 & 153 & 62 & 115 & 23 & 9 & 130 & 53 \\
East Asia & 1230 & 24 & 2 & 1817 & 610 & 50 & -587 & -48 \\
South East Asia & 298 & 138 & 46 & 252 & 92 & 31 & 46 & 15 \\
South Asia & 249 & 4 & 2 & 344 & 99 & 40 & -95 & -38 \\
Europe & 620 & 55 & 9 & 1191 & 626 & 101 & -571 & -92 \\
North America & 1567 & 60 & 4 & 1922 & 415 & 26 & -355 & -23 \\
Russia & 840 & 350 & 42 & 520 & 30 & 4 & 320 & 38 \\
South America & 357 & 171 & 48 & 223 & 37 & 10 & 134 & 38 \\
Central America & 35 & 14 & 41 & 52 & 31 & 90 & -17 & -49 \\
Eastern Europe & 39 & 1 & 4 & 69 & 31 & 78 & -29 & -74 \\
West Asia & 1247 & 759 & 61 & 547 & 60 & 5 & 699 & 56 \\
\hline Global & 7293 & 2090 & 29 & 7293 & 2090 & 29 & 0 & 0 \\
\hline
\end{tabular}

than production-based emissions, with the opposite holding in developing countries. Although growth of emissions occurring within these developed countries has slowed in some cases, the emissions related to goods and services consumed in these regions has continued to grow with increased imports of embodied emissions (Fig. 1). Steinberger et al. (2012) explore these differences in terms of indicators of human development. Despite the rapid growth in embodied emissions, it is important to recall that territorial emissions to meet domestic consumption are still the largest contributor to consumption-based emissions in most countries. The growth in the emission transfers do, however, have a significant impact on regional emissions growth, and are therefore highly relevant to the design of effective climate policies (Peters and Hertwich, 2008b; Hertwich and Peters, 2009; Davis and Caldeira, 2010; Peters et al., 2011b; Caldeira and Davis, 2011; Davis et al., 2011).

\section{Physical Flows of Carbon}

\subsection{Fossil fuels}

Global trade in fossil fuels is substantial and growing (BP, 2011). A recent study that analysed $\mathrm{CO}_{2}$ emissions from the burning of fossil fuels according to where the fuels were extracted found that, in 2004, $2.8 \mathrm{GtC}$ emissions (37\% of global emissions that year) were from burning of fuels that had been traded internationally (Davis et al., 2011). While several Material Flow Analyses (MFAs) have investigated fossil fuels (e.g. Bringezu et al., 2004; Dittrich and Bringezu, 2010; Bruckner et al., 2012), Davis et al. (2011) remains the only analysis of the physical flow of carbon in traded fossil fuels; that is, Davis et al. (2011) aggregated the fossil fuels by carbon content and not mass or energy content. The MFA studies generally use simplified trade analysis based on apparent consumption, while Davis et al. (2011) used a detailed MRIO attribution model including the conversion and trade in both primary and secondary fuels (e.g. refining of crude oil into gasoline). Thus, refined petroleum is allocated back to the country of primary fuel extraction (Davis et al., 2011). The results of Davis et al. (2011) show the geographical concentration of fossil fuel resources: fuels extracted in China, the USA, the Middle East (a region of 13 countries), Russia, Canada, Australia, India and Norway account for $67 \%$ of global $\mathrm{CO}_{2}$ emissions. Oil and its refined products dominate international trade in fossil carbon $\left(7.0 \mathrm{GtCO}_{2}\right.$ in 2004), but international markets for coal $\left(1.8 \mathrm{GtCO}_{2}\right)$ and natural gas $\left(1.5 \mathrm{GtCO}_{2}\right)$ are substantial and growing (BP, 2011). For this paper we updated the results of Davis et al. (2011) to include the most recent data updates and present the results by primary fossil fuels (coal, crude oil, and gas). The updated results are very similar to the original results, but provide more detail. In 2004, $2.7 \mathrm{GtC}$ (37\% of global emissions that year) were from burning of fuels that were traded internationally. In this section, we focus on the results from the extraction of fossil fuels to the point of energy consumption (or emission production). Davis et al. (2011) additionally link the results from energy consumption to emissions consumption (embodied $\mathrm{CO}_{2}$ emissions, as described in the previous section).

Table 8 shows the results for the extended RECCAP regions. The largest extraction occurs in North America 

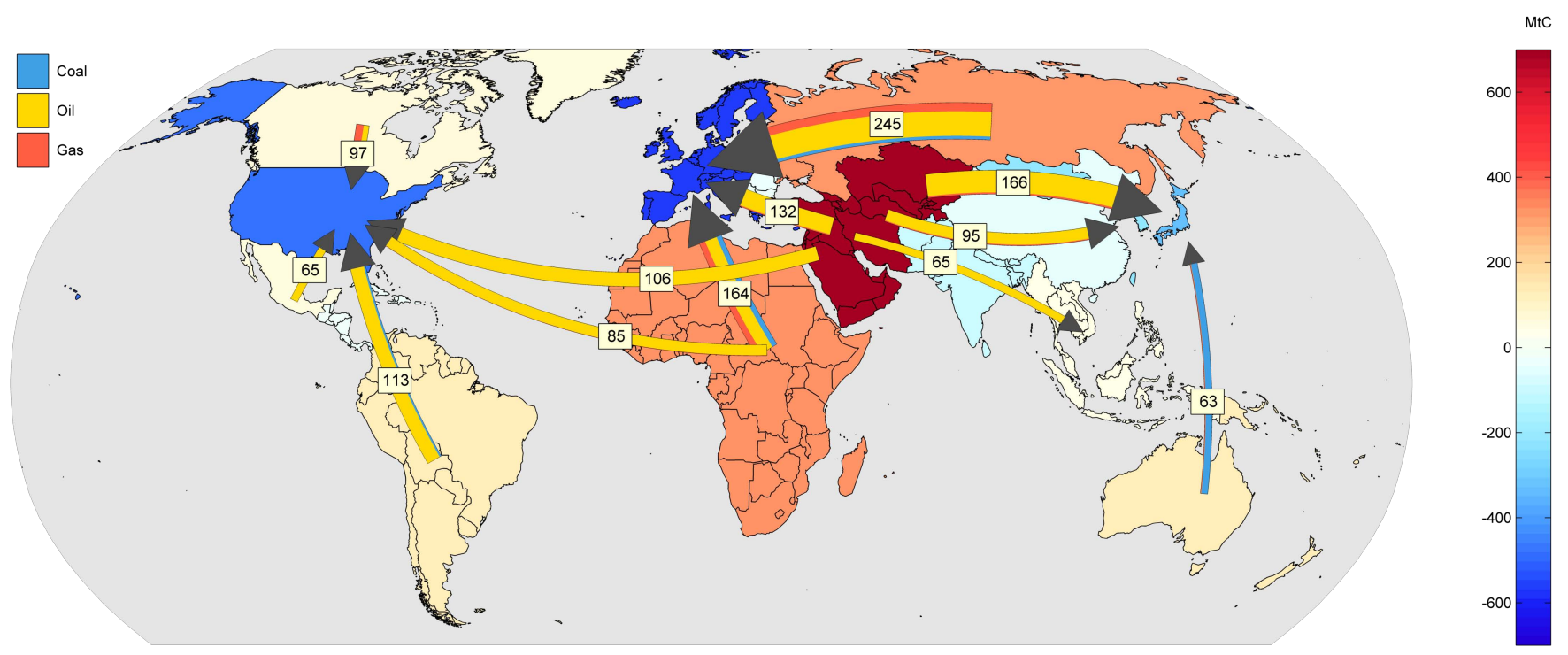

Fig. 9. The top 12 inter-regional flows of fossil fuel carbon embodied in trade from extracting region to producing region, broken down by primary fuel type, and disaggregated further to highlight key countries (2004). With Japan and China separated, the largest single interregional flow is from Russia to Europe ( $245 \mathrm{MtC}$ ), primarily oil and gas. This grouping also highlights that most of the emissions imports to North America are in fact to USA.

Table 9. The 2004 fossil fuel carbon used as feedstock in each region (production), the amount and share exported, the consumption of feedstock for products (consumption) amount and share imported, and the difference between production and consumption (and exports and imports). Exports and imports only represent the trade between the RECCAP regions, and do not include the trade between countries within a region (e.g. Finland and Sweden). The shares are always in terms of production.

\begin{tabular}{lrrr|rrr|rr}
\hline & \multicolumn{2}{c}{ Production } & \multicolumn{2}{c|}{ Consumption } & \multicolumn{2}{c}{ Balance } \\
\cline { 2 - 8 } Region & $\begin{array}{r}\text { Production } \\
(\mathrm{MtC})\end{array}$ & $\begin{array}{r}\text { Exports } \\
(\mathrm{MtC})\end{array}$ & $\begin{array}{r}\text { Share } \\
(\%)\end{array}$ & $\begin{array}{r}\text { Consumption } \\
(\mathrm{MtC})\end{array}$ & $\begin{array}{r}\text { Imports } \\
(\mathrm{MtC})\end{array}$ & $\begin{array}{r}\text { Share } \\
(\%)\end{array}$ & $\begin{array}{r}\text { Balance } \\
(\mathrm{MtC})\end{array}$ & $\begin{array}{r}\text { Share } \\
(\%)\end{array}$ \\
\hline Africa & 6 & 2 & 30 & 10 & 6 & 93 & -4 & -64 \\
Oceania & 2 & 1 & 32 & 5 & 3 & 138 & -3 & -106 \\
East Asia & 88 & 31 & 35 & 75 & 18 & 20 & 13 & 15 \\
South East Asia & 20 & 13 & 65 & 13 & 6 & 28 & 7 & 36 \\
South Asia & 16 & 4 & 27 & 16 & 5 & 31 & -1 & -3 \\
Europe & 66 & 17 & 26 & 85 & 36 & 55 & -19 & -29 \\
North America & 103 & 20 & 19 & 113 & 30 & 29 & -10 & -10 \\
Russia & 17 & 10 & 59 & 10 & 2 & 14 & 8 & 45 \\
South America & 11 & 3 & 29 & 13 & 5 & 41 & -1 & -13 \\
Central America & 5 & 2 & 36 & 5 & 2 & 32 & 0 & 4 \\
Eastern Europe & 2 & 1 & 55 & 3 & 2 & 72 & 0 & -17 \\
West Asia & 30 & 18 & 60 & 20 & 8 & 27 & 10 & 33 \\
\hline Global & 367 & 122 & 33 & 367 & 122 & 33 & 0 & 0 \\
\hline
\end{tabular}

(1.6 GtC), followed by similar values in West Asia (1.2 GtC) and East Asia (1.2 GtC). Most of the extraction in North America is used domestically ( $4 \%$ exported), and this similarly occurs in East Asia (2\% exported). In West Asia most of the carbon is exported ( $759 \mathrm{MtC}, 61 \%$ of extraction) and other regions exporting a large share of their extraction are the Russian region ( $350 \mathrm{MtC}, 42 \%$ ), Africa ( $362 \mathrm{MtC}, 64 \%$ ), Oceania (153 MtC, $62 \%)$ and South America (171 MtC,
$42 \%)$. Key importers of fossil fuels are Europe (626 MtC), which imports as much as it extracts; East Asia $(610 \mathrm{MtC})$, which imports $50 \%$ of its extraction; and North America (415 MtC), which imports $25 \%$ of its domestic extraction. Even though North America imports large amounts of fossil fuels, it is less dependent on imported sources of fossil fuels measured in terms of carbon than many other regions. Europe, East Asia, and North America are the largest 
net importers and West Asia, Africa, and the Russian region are the largest net exporters of carbon. These results change when production is further linked to consumption to provide the full link from the extraction of fossil fuels to the point of consumption of goods and services (Davis et al., 2011).

Figure 9 shows the top 12 inter-regional flows disaggregated by fuel type (coal, oil, gas) between the extended RECCAP regions (USA, Canada, Japan, China disaggregated). The total trade between all 112 countries and regions in the database is $2.7 \mathrm{GtC}$ ( $37 \%$ total emissions), but due to intraregional trade flows this is lower at $2.1 \mathrm{GtC}(29 \%)$ between the RECCAP regions. The largest flow is from the Russian region to Europe (245 MtC) dominated by oil and some gas. There are many large flows from West Asia, mainly oil, with the largest to Japan (165 MtC) and Europe (132 MtC). Africa has a large export to Europe (163 MtC) with a mix of coal, oil, and gas, and a large export of oil to North America $(85 \mathrm{MtC})$. There are large imports into Europe dominated by the Russian region, Africa, and Middle East. North America has more varied imports from Canada, Mexico, South America, and Africa. Australia has a large export of coal to Japan (62 MtC). These flows reflect the location of fossil resources together with the demand for fossil fuel above domestic resources.

\subsection{Petroleum-derived products}

Carbon is traded in petroleum-derived products such as plastics, fertilisers (e.g. ammonia and urea), and fuels (e.g. methanol), though we are unaware of studies that attempt to estimate the amount of carbon in these products that enters international trade. The GTAP-MRIO emission dataset (Peters et al., 2011a) includes estimates of the fossil carbon used as feedstock into chemical industries. The feedstocks are consistent with the feedstocks removed from the analysis in the study on trade in fossil fuel carbon (Davis et al., 2011) and presented in the previous section.

We estimate that in 2004 there was approximately $367 \mathrm{MtC}$ physically embedded in petroleum-derived products. Of this, we found that $183 \mathrm{MtC}$ (50\% of the carbon in that year) were in petroleum-derived products traded internationally, with this amount reducing to $122 \mathrm{MtC}$ (33\%) due to intra-regional trade for the RECCAP regions. Table 9 shows the results for the RECCAP regions. North America has the largest production of feedstocks for products (103 MtC), followed by East Asia $(88 \mathrm{MtC})$ and Europe $(66 \mathrm{MtC})$. North America and Europe use most of their feedstocks domestically and supplement them with net imports. Trade flows in other regions are larger relative to North America and Europe. The largest export is from East Asia to North America $(12 \mathrm{MtC})$ and East Asia to Europe $(9 \mathrm{MtC})$. North America exports to Europe ( $9 \mathrm{MtC}$ ) and Europe back to North America $(6 \mathrm{MtC})$, giving a much smaller net export from North America to Europe ( $3 \mathrm{MtC})$. Likewise, North America exports back to East Asia (5 MtC), giving a net flow of car- bon from East Asia to North America (7 MtC). The Russian region exports a large amount to Europe $(4 \mathrm{MtC})$ which accounts for almost half of the region's exports. Despite large trade flows relative to production, considerably less carbon is traded internationally in petroleum-derived products compared to fossil fuel carbon (petroleum-derived products are only about $5 \%$ of fossil fuel carbon extracted). Since this is the first study on physically embedded flows in petroleumderived products, more analysis is needed to confirm our results.

\subsection{Biomass Flows}

In this section we consider physical flows of carbon via trade in biomass: harvested wood products (HWPs), crops, and feed used for livestock. Following the convention in emission statistics (IPCC, 2006), we assume that carbon emissions from oxidising biomass are sequestered soon after in the regrowth of the biomass (carbon neutral). In reality, there is a time-lag between oxidation and regrowth, but we do not consider that here (Cherubini et al., 2011).

Since we use the GTAP-MRIO to allocate carbon from biomass flows, we expect to get different results from previous studies as we include a high level of processing. In the GTAP-MRIO the biomass carbon is allocated to the sector that harvests it, and then the GTAP-MRIO reallocates it to the sectors that consume the carbon. Most studies on biomass flows in the literature only consider apparent consumption and thus do not include processing (e.g. Bringezu et al., 2004; Ciais et al., 2007, 2008; Krausmann et al., 2008; Erb et al., 2009; Dittrich and Bringezu, 2010). Some studies on apparent consumption, however, have considered multiple trade links (Kastner et al., 2011a, b) which can be considered as a type of processing. Since the GTAP-MRIO considers multiple trade links, and multiple levels of processing between products, it is expected that the GTAP-MRIO would allocate a larger share to international trade compared to other studies in the literature.

To explore the differences between studies in more detail, we allocate the carbon to countries using three different approaches with the GTAP-MRIO:

1. Our standard approach, as presented in Table 10, is based on a full GTAP-MRIO model which considers full processing along the global supply chain. Our method captures trade in a wide range of sectors even if they are not clearly identified as containing biomass; for example, miscellaneous toys and books would be included.

2. We also use a method called Emissions Embodied in Bilateral Trade (EEBT) which considers the domestic (not global) supply chain and thus contains a lower level of processing (Peters, 2008; Peters and Hertwich, 2008b). It is not possible to determine in advance if the MRIO or EEBT method gives a higher estimate, as it 
Table 10. The 2004 industrial roundwood extracted in each region (production) in terms of carbon, the amount and share exported, the consumption amount and share imported, and the difference between production and consumption (and exports and imports). Exports and imports only represent the trade between the RECCAP regions, and do not include the trade between countries within a region (e.g. Finland and Sweden). The shares are always in terms of production.

\begin{tabular}{lrrr|rrr|rr}
\hline & \multicolumn{2}{c}{ Production } & \multicolumn{2}{c|}{ Consumption } & \multicolumn{2}{c}{ Balance } \\
\cline { 2 - 9 } Region & $\begin{array}{r}\text { Production } \\
\text { (MtC) }\end{array}$ & $\begin{array}{r}\text { Exports } \\
(\mathrm{MtC})\end{array}$ & $\begin{array}{r}\text { Share } \\
(\%)\end{array}$ & $\begin{array}{r}\text { Consumption } \\
(\mathrm{MtC})\end{array}$ & $\begin{array}{r}\text { Imports } \\
(\mathrm{MtC})\end{array}$ & $\begin{array}{r}\text { Share } \\
(\%)\end{array}$ & $\begin{array}{r}\text { Balance } \\
(\text { MtC) }\end{array}$ & $\begin{array}{r}\text { Share } \\
(\%)\end{array}$ \\
\hline Africa & 19 & 4 & 22 & 17 & 3 & 14 & 1 & 8 \\
Oceania & 11 & 4 & 35 & 9 & 2 & 16 & 2 & 20 \\
East Asia & 25 & 9 & 34 & 42 & 25 & 99 & -17 & -65 \\
South East Asia & 22 & 14 & 66 & 9 & 2 & 8 & 13 & 58 \\
South Asia & 8 & 1 & 10 & 10 & 3 & 36 & -2 & -26 \\
Europe & 72 & 11 & 15 & 86 & 25 & 34 & -14 & -19 \\
North America & 138 & 14 & 10 & 143 & 19 & 14 & -5 & -4 \\
Russian Region & 31 & 18 & 58 & 15 & 2 & 5 & 17 & 53 \\
South America & 38 & 9 & 25 & 30 & 1 & 3 & 8 & 22 \\
Central America & 1 & 0 & 29 & 2 & 1 & 105 & -1 & -76 \\
Eastern Europe & 5 & 3 & 56 & 3 & 1 & 15 & 2 & 42 \\
West Asia & 3 & 1 & 21 & 8 & 6 & 190 & -5 & -170 \\
\hline Global & 373 & 88 & 24 & 373 & 88 & 24 & 0 & 0 \\
\hline
\end{tabular}

depends on how much trade a country has in intermediate (semi-processed) products (Peters, 2008; Kanemoto et al., 2012).

3. To determine the effects of using apparent consumption (that is, without further processing of traded products), we have also estimated trade flows using the monetary trade data from the GTAP-MRIO only (TRADE). For this, we distribute the carbon directly to each sector according to the share of exports from that sector and we distribute the exports according to the bilateral trade data. In the case of HWPs, we distribute the forest harvest over both the forestry and wood and paper products sectors (not just the default to the forestry sector).

The results from these three approaches are compared to results from independent studies.

\subsubsection{Harvested Wood Products}

\section{Estimates of carbon flows in harvested wood products}

We linked the GTAP-MRIO to harvested wood products (industrial roundwood) to estimate the carbon traded via harvest wood products (HWPs). In this analysis we only consider the transport of carbon between regions, and we do not estimate when that carbon maybe emitted to the atmosphere. The release of carbon to the atmosphere will depend on the decay times of the different product pools (Pingoud et al., 2006; Cherubini et al., 2012).

Table 10 shows the industrial roundwood in terms of carbon that is harvested, consumed, exported, and imported into each region. Globally, we find that $373 \mathrm{MtC}$ are extracted, with the largest extraction occurring in North America (138 MtC) followed by Europe (72 MtC), South America (38 MtC), and then the Russian region $(31 \mathrm{MtC})$. The ranking is only slightly changed when using a consumption basis, with North America having a small net import to increase its contribution (to $143 \mathrm{MtC}$ ), Europe also having a net import increasing its share $(86 \mathrm{MtC})$, East Asia having a large increase in its contribution (42 Mt) representing a net import of $65 \%$ of its harvest, and South America having a slight decrease $(30 \mathrm{MtC})$ representing a net export. The largest importer is North America (143 MtC), followed by Europe (86 MtC) and East Asia (42 MtC). The regions with the largest differences between production and consumption in absolute terms are the Russian region (exporter), East Asia (importer), Europe (exporter), and South East Asia (importer). Countries with small domestic forestry sectors, such as in West Asia and Central America, have large relative imports.

We estimate the global trade in HWPs to be $148 \mathrm{MtC}$ (40\% of global production), though when aggregating to RECCAP regions, many of the intra-region flows cancel leaving $88 \mathrm{MtC}$ ( $24 \%$ of the global total; Table 10). The intra-regional flow can be considerable: for example, including intra-regional flows increases North America's exports from $14 \mathrm{MtC}$ to $40 \mathrm{MtC}$ mainly due to a large flow from Canada to the USA ( $22 \mathrm{MtC})$. Figure 10 shows the largest inter-regional trade flows. The Russian region is the largest exporter of HWPs (18 MtC, $58 \%$ of total), with large flows to East Asia (6.2 MtC), Europe (5.9 MtC), and a smaller flow to North America $(1.8 \mathrm{MtC})$. South East Asia is the next 

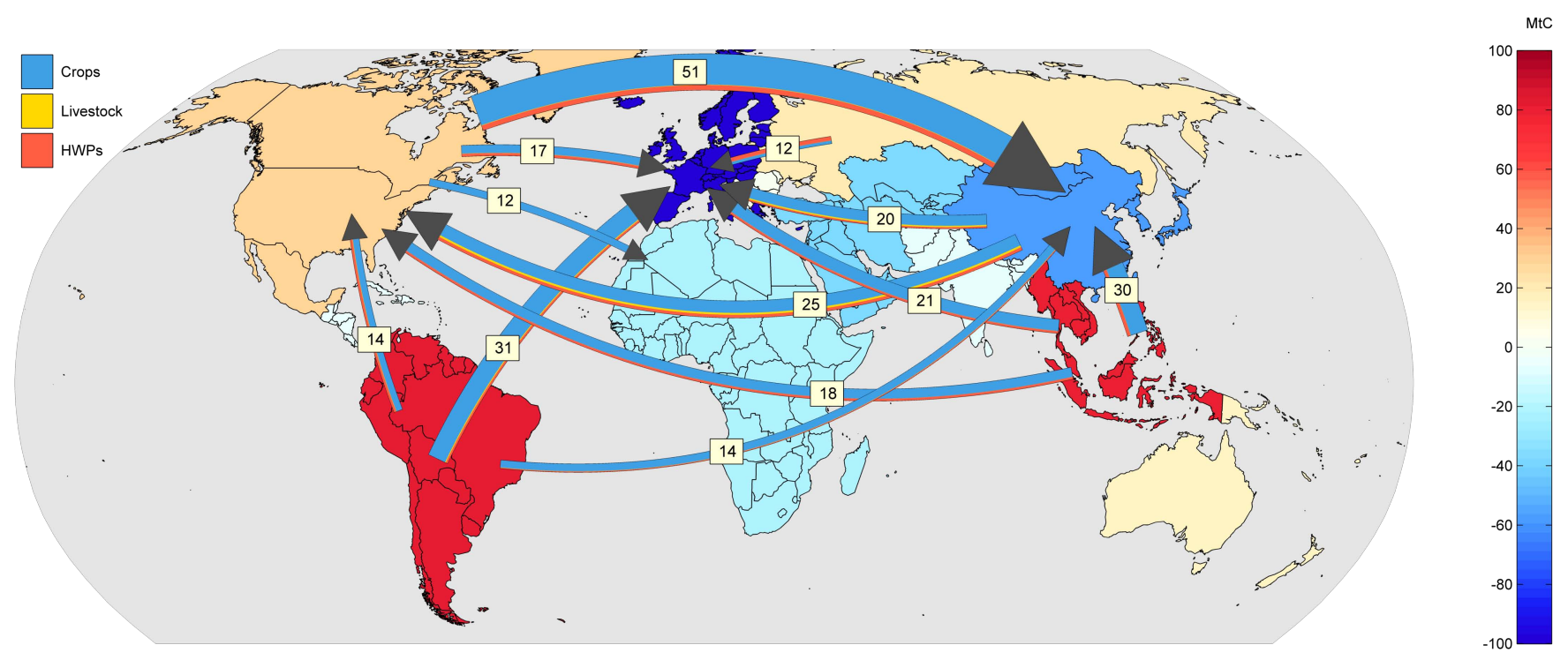

Fig. 10. The top 10 flows for carbon flows in HWPs, crops, and livestock products (2004). The region colours represent the net flows out of each RECCAP region (Table 13). The colours of the arrows refer to the different types of carbon flows. Most flows are dominated by carbon in crops, then HWPs, with the carbon in livestock products much smaller.

biggest exporter (14 MtC, $66 \%$ of total), with large flows to East Asia (4.6 MtC), North America (3.1 MtC), and Europe $(2.5 \mathrm{MtC})$. The third and fourth largest exporters (North America and Europe) do not appear in many of the top flows, indicating that these regions export to a wide range of other regions. The fifth largest exporter is South America (9 MtC, $25 \%$ of total), with the largest flows to North America $(3.4 \mathrm{MtC})$ and Europe $(2.5 \mathrm{MtC})$. The large flow from Oceania represents exports from Australia and New Zealand. To put the inter-regional flows into perspective, the largest intra-regional flow at the disaggregate level is from Canada to the USA $(22 \mathrm{MtC})$, much larger than any single inter-regional flow. In addition, the inter-regional flows can differ substantially depending on how the results are allocated. For example, the second largest inter-regional flow is from China to the USA (3.6 MtC), which is not seen in the RECCAP results as it is offset by trade in the aggregated regions, for example, from USA to Japan (3.1 MtC, third largest flow). Thus, care needs to be taken if interpreting the inter-regional flows in country specific applications.

\section{Comparisons with other studies}

We are not aware of many studies that consider international trade in harvested wood products (HWPs) at the international level. We compare three methods of allocation using the GTAP-MRIO with the results of Kastner et al. (2011a) and Ciais et al. (2008) in Fig. 11. Both of these authors use an apparent consumption approach, though Kastner et al. (2011a) consider multiple levels of trade (but not processing). Figure 11 shows a relatively large spread between the estimates.
Our MRIO and EEBT approaches generally give larger net flows, and they are of similar magnitude and sign, except for China. We find a total global trade flow of $148 \mathrm{MtC}$ for the MRIO method and $153 \mathrm{MtC}$ for the EEBT method. The TRADE approach gives a trade flow of $105 \mathrm{MtC}$, less than the MRIO and EEBT methods, but this is expected as it does not include processing. In most cases, TRADE also gives smaller estimates at the country level. All three methods give a similar trend for the countries shown. Ciais et al. (2008) only consider European countries with a base year of 1997. They use an apparent consumption approach and their estimates are generally in line with the other results for the countries considered. There is no clear trend on whether their approach is better approximated by any of our three methods.

Kastner et al. (2011a) estimates a total global trade of 129 $\mathrm{MtC} \mathrm{yr}^{-1}$ averaged over 1997-2007, representing 33\% of the total extraction (our MRIO found $149 \mathrm{MtC}$ or $40 \%$ in 2004). It is expected that the method of Kastner et al. (2011a) is lower than our MRIO method as they do not include processing between industry sectors. At the country level, we find much larger variations between Kastner et al. (2011a) and our estimates (Fig. 11). China, for example, differs in size and considerably in magnitude (net importer of $-21 \mathrm{MtC}$ in Kastner et al. (2011a) net exporter of $3 \mathrm{MtC}$ in the GTAPMRIO). There are other significant outliers for the Russian Federation, Indonesia, Chile, Korea, Japan, and the USA. In the particular case of China, there is considerable processing of raw materials before export as manufactured products and different levels of processing may be the underlying cause of the differences we report. However, it is not possible to conclusively determine without further analysis what the cause of the difference is. For many other countries, their results. 


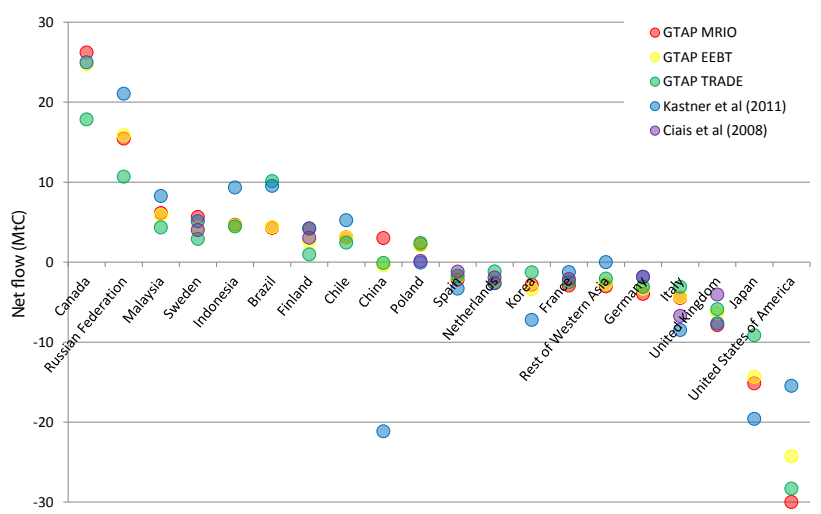

Fig. 11. A comparison of different methods of estimating the trade in harvested wood products (HWPs) for the 20 largest net (exports minus imports) flows (see text). The Ciais et al. (2008) results are for 1997, while all other studies are for 2004.

differ from our three methods, and there is not a clear trend on whether any of our methods better approximate the results of Kastner et al. (2011a).

Overall, Fig. 11 shows that the carbon fluxes between regions follow similar trends for all the methods used, though the results of Kastner et al. (2011a) exhibit greater variability. Further investigation is required to understand these differences.

\subsubsection{Crops}

\section{Estimates of carbon flows in crops}

We linked the GTAP-MRIO to crop production data to estimate the physical carbon flows via crops. Table 11 shows crops in terms of carbon that is extracted (produced), consumed, exported, and imported into each region. Globally, we find that $1704 \mathrm{MtC}$ are extracted, with the largest extraction occurring in East Asia (329 MtC) followed by North America (265 MtC), South East Asia (221 MtC), South Asia (208 MtC), South America (168 MtC), and then Africa $(158 \mathrm{MtC})$. The ranking is only slightly changed from a consumption basis, with East Asia having net imports to increase its share ( $375 \mathrm{MtC})$, Europe increasing its contribution (246 MtC) through a large net import (83 MtC), North America decreasing its contribution (226 Mt) with a net export, South Asia having a similar contribution (213 MtC), Africa having a net import to increase its contribution to (182 MtC), South East Asia having a net export decreasing its contribution $(152 \mathrm{MtC})$, and South America having a large net export decreasing its contribution $(96 \mathrm{MtC})$. The regions with the largest differences between production and consumption in absolute terms are Europe (importer), South America (exporter), South East Asia (exporter), East Asia (importer), and North America (export). Countries with a small domestic crop sector compared to population have large relative im- ports, such as West Asia and Europe. Oceania and South America both have a net export of around $50 \%$ of their production.

We estimate the global trade in crops to be $522 \mathrm{MtC}$ (31\% of global total), though when aggregating to RECCAP regions, many of the intra-regional flows cancel leaving $396 \mathrm{MtC}$ traded (23\% of the global total; Table 11). Figure 10 shows the largest inter-regional trade flows. North America is the largest exporter of crop carbon $(92 \mathrm{MtC}$, $35 \%$ of the South East Asian total), with large flows to East Asia (26 MtC), Africa (10 MtC), and Europe (10 MtC). South East Asia is the next biggest exporter (83 MtC, $38 \%$ of the North American total), with large flows to East Asia (21 MtC), Europe (17 MtC), and North America (11 MtC). The third largest exporter is South America (79 MtC, $47 \%$ ), with large flows to Europe (26 MtC), East Asia (11 MtC), and Africa $(10 \mathrm{MtC})$. East Asia is the fourth largest exporter (49 MtC, $15 \%$ ), with a large flow to Europe (14 MtC). The largest importer is Europe ( $99 \mathrm{MtC}$ ), followed closely by East Asia (95 MtC), and then North America (53 MtC), Africa (39 MtC), and West Asia (38 MtC). These intra-regional flows hide the most significant inter-regional flows. The largest regional flows are from the USA to Japan (22 MtC) and China to Japan (15 MtC). These individual flows can be as large as the intra-regional flows as they tend to cancel; for example, the USA to Japan flow is partially compensated by flow from China to the USA ( $8 \mathrm{MtC})$. Thus, the RECCAP inter-regional flows can mask significant and more policyrelevant flows between individual countries in and between the RECCAP regions.

A small part of the crop carbon from Table 11 represents crops that are fed to livestock; $244 \mathrm{MtC}$ out of $1704 \mathrm{MtC}$ of crops $(14 \%)$ or $3236 \mathrm{MtC}$ of livestock carbon consumption $(7.5 \%)$. We did not reallocate this to livestock and thus it remains in the crop data. Since we estimate the carbon flows associated with livestock using a feed demand model, this does not affect the livestock results. Foley et al. (2011) report that $35 \%$ of global crop production is used for animal feed and Ciais et al. (2007) report $29 \%$. Our estimate of $244 \mathrm{MtC}$ out of $1704 \mathrm{MtC}$ of crops $(14 \%)$ is considerably lower than these estimates, but our results are consistent with the FAO data we used (FAO, 2012a). Our input data for crops considers crops primarily used for human consumption and has less detail on animal feed and fodder ${ }^{4}$. Thus, we assume livestock feed is primarily estimated using the feed model presented earlier.

\section{Comparisons with previous studies}

Figure 12 shows a comparison of different methods and estimates of carbon trade in crops. We show three methods based on the GTAP database - MRIO, EEBT, and TRADE as explained earlier - and we show independent results from

\footnotetext{
${ }^{4}$ http://faostat.fao.org/site/362/DesktopDefault.aspx? PageID $=\underline{362}$
} 
Table 11. The 2004 crops extracted in each region (production) in terms of carbon, the amount and share exported, the consumption amount and share imported, and the difference between production and consumption (and exports and imports). Exports and imports only represent the trade between the RECCAP regions, and do not include the trade between countries within a region (e.g. Finland and Sweden). The shares are always in terms of production.

\begin{tabular}{lrrr|rrr|rr}
\hline & \multicolumn{3}{c}{ Production } & \multicolumn{2}{c|}{ Consumption } & \multicolumn{2}{c}{ Balance } \\
\cline { 2 - 9 } Region & $\begin{array}{l}\text { Production } \\
(\mathrm{MtC})\end{array}$ & $\begin{array}{r}\text { Exports } \\
(\mathrm{MtC})\end{array}$ & $\begin{array}{r}\text { Share } \\
(\%)\end{array}$ & $\begin{array}{r}\text { Consumption } \\
(\mathrm{MtC})\end{array}$ & $\begin{array}{r}\text { Imports } \\
(\mathrm{MtC})\end{array}$ & $\begin{array}{r}\text { Share } \\
(\%)\end{array}$ & $\begin{array}{r}\text { Balance } \\
(\mathrm{MtC})\end{array}$ & $\begin{array}{r}\text { Share } \\
(\%)\end{array}$ \\
\hline Africa & 158.4 & 15.6 & 10 & 182.1 & 39.3 & 25 & -23.7 & -15 \\
Oceania & 22.5 & 16.9 & 75 & 11.2 & 5.5 & 24 & 11.4 & 50 \\
East Asia & 329.2 & 49.1 & 15 & 375.0 & 94.8 & 29 & -45.7 & -14 \\
South East Asia & 221.2 & 83.1 & 38 & 152.8 & 14.7 & 7 & 68.3 & 31 \\
South Asia & 207.9 & 10.9 & 5 & 213.1 & 16.0 & 8 & -5.1 & -2 \\
Europe & 163.2 & 16.1 & 10 & 246.3 & 99.3 & 61 & -83.1 & -51 \\
North America & 264.6 & 91.6 & 35 & 226.3 & 53.2 & 20 & 38.4 & 15 \\
Russia & 69.9 & 15.9 & 23 & 65.7 & 11.7 & 17 & 4.2 & 6 \\
South America & 167.6 & 79.3 & 47 & 96.2 & 7.9 & 5 & 71.4 & 43 \\
Central America & 15.1 & 4.6 & 30 & 20.1 & 9.5 & 63 & -4.9 & -33 \\
Eastern Europe & 25.7 & 5.2 & 20 & 25.7 & 5.2 & 20 & -0.1 & 0 \\
West Asia & 58.4 & 7.5 & 13 & 89.3 & 38.4 & 66 & -30.9 & -53 \\
\hline Global & 1703.7 & 395.6 & 23 & 1703.7 & 395.6 & 23 & 0.0 & 0 \\
\hline
\end{tabular}

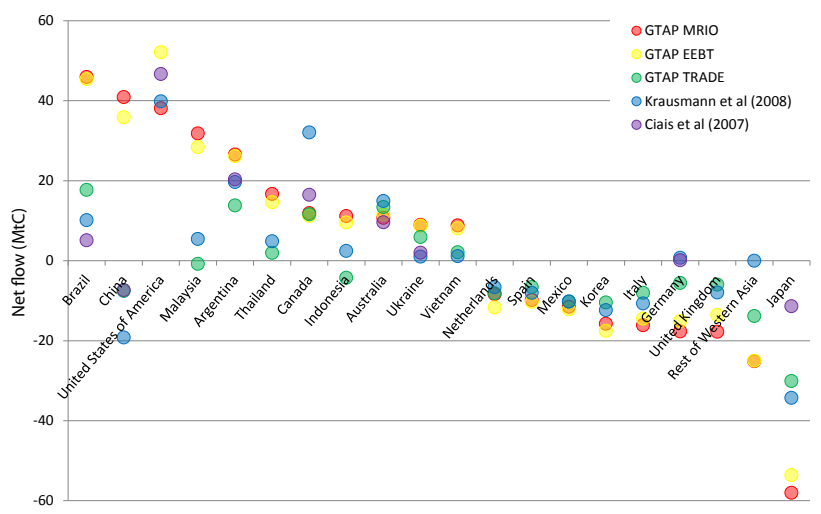

Fig. 12. A comparison of different methods of estimating the carbon trade in crops for the 20 largest net (exports minus imports) flows (see text). The Ciais et al. results are for 1997, Krausmann et al. for 2008, and the MRIO, EEBT, and TRADE results are for 2004.

Krausmann et al. (2008) and Ciais et al. (2007). We convert the results of Krausmann et al. (2008) into carbon using a dry matter to carbon conversion of $0.45 \mathrm{tC} / \mathrm{tDM}$. Krausmann et al. (2008) estimate crop harvest as $1544 \mathrm{MtC}$ and crop trade as $393 \mathrm{MtC}$, comparable to our estimates of 1704 and $396 \mathrm{MtC}$. We could expect similarity in the crop harvest due to the use of similar input data, but the similarity in the total trade may simply be chance, given large differences in methodology; this is clearly seen at the country level, where there are marked variations. Ciais et al. (2007) estimate crop harvest of $1290 \mathrm{MtC}$ for 1998 and trade of $174 \mathrm{MtC}$. This is lower than our estimate and Krausmann et al. (2008) as Ciais et al. (2007) only consider a subset of all crops.
Figure 12 shows a high degree of scatter in the results at the country level, although these can largely be explained by the background methodologies. The GTAP-MRIO and GTAP-EEBT approaches both consider a high level of processing (for example, carbon from crops that are embodied in clothing). When using the TRADE method to approximate apparent consumption, it is found that it is quite close to the estimates of Krausmann et al. (2008) and Ciais et al. (2007). This supports the conclusion that the variation in the results is due to a different definition of consumption: apparent versus final consumption. Thus, based on this comparison, it would appear that processing is particularly important in estimating the physical carbon flows between regions.

\subsubsection{Livestock products}

\section{Estimates of carbon flows in livestock products}

Finally, we linked the GTAP-MRIO to a model on biomass consumption by livestock and conversion efficiencies to livestock products to estimate the carbon traded in livestock products. Globally, we estimate that $3236 \mathrm{MtC}$ are consumed by livestock. After adjusting for the conversion efficiency of biomass into livestock products, we estimate that $129 \mathrm{MtC}$ remain in the livestock products. The global average conversion efficiency is $4 \%$, but varies from $1.1 \%$ in Sub-Saharan Africa to $9.2 \%$ in Eastern Europe (Krausmann et al., 2008).

Table 12 shows the carbon in livestock products that are produced, consumed, exported, and imported into each region. Globally, we find that $129 \mathrm{MtC}$ are in livestock products, with the largest production occurring in East Asia $(26 \mathrm{MtC})$ followed by North America $(25 \mathrm{MtC})$, 
Europe (25 MtC), South America (13 MtC), and South Asia $(12 \mathrm{MtC})$. The ranking is changed when allocated to the region where the livestock products are consumed. North America and Europe both have increases in their allocation (29 MtC for North America and $28 \mathrm{MtC}$ for Europe) due to net imports of $3 \mathrm{MtC}$, while East Asia has a decreases in its contribution $(22 \mathrm{MtC})$ through a net export $(4 \mathrm{MtC})$. South Asia decreases its contribution slightly $(11 \mathrm{MtC})$ due to a net import $(0.5 \mathrm{MtC})$; South America decreases its contribution $(10 \mathrm{MtC})$ through a net export $(3 \mathrm{MtC})$; and West Asia has an increase in its contribution $(8 \mathrm{MtC})$ due to a net import $(2 \mathrm{MtC})$. The regions with the largest differences between production and consumption in absolute terms are East Asia (exporter), North America (importer), Europe (importer), and South America (exporter). Countries with a small domestic livestock sector compared to consumption have large relative imports, such as West Asia (28\%) and Central America $(21 \%)$. Oceania has a net export of around $41 \%$ of their production, and South America $22 \%$.

We estimate the global trade in livestock carbon to be $28 \mathrm{MtC}$ ( $22 \%$ of global total), though when aggregating to RECCAP regions, some of the intra-regional flows cancel leaving $17 \mathrm{MtC}$ traded (13\% of the global total; Table 12). Figure 10 shows the largest inter-regional trade flows. East Asia is the largest exporter of livestock carbon (6 MtC, $23 \%$ of total), with largest flows to North America and Europe ( $2 \mathrm{MtC}$ each), and West Asia $(0.3 \mathrm{MtC})$. South America is the next biggest exporter ( $3 \mathrm{MtC}, 24 \%$ of total), with largest flows to Europe (1 MtC), and North America and West Asia $(0.4 \mathrm{MtC}$ each). The largest net importers are Europe and North America ( $5 \mathrm{MtC}$ each), followed by East Asia and West Asia (2 MtC each). These intra-regional flows hide the most significant inter-regional flows. The largest regional flows are from China to the USA ( $2 \mathrm{MtC}$ ) and China to Japan $(1 \mathrm{MtC})$. These individual flows can be as large as the intraregional flows as they tend to cancel. Thus, the RECCAP inter-regional flows can mask significant and more policyrelevant flows between individual countries in and between the RECCAP regions.

\section{Comparisons with previous studies}

We are not aware of other global studies that track carbon in livestock products.

\subsubsection{Combined carbon in biomass flows}

Table 13 shows the aggregated flows of forests, crops, and livestock carbon (Table 10, Table 11, and Table 12). These tables show the carbon physically within products that enter the economic system and hence trade flows. If we do not consider the livestock conversion efficiencies (that is, consider biomass consumed by livestock and not the carbon in livestock products) we estimate the total carbon in biomass flows as $5.3 \mathrm{GtC}$ for 2004, comparable with the used extraction of $5.5 \mathrm{GtC}$ for 2000 in Krausmann et al. (2008). Krausmann et al. (2008) estimate trade in plant biomass as $393 \mathrm{MtC}$ (crops and forests), which is less than our estimate for crops and forests (484 MtC, Table 10 and Table 11). Since Krausmann et al. use apparent consumption, we expect their estimate to be lower.

The actual carbon fluxes between regions (Table 13) are particularly important for balancing regional carbon balances. We find that the largest net exporters of carbon are South America $(83 \mathrm{MtC})$ and South East Asia $(81 \mathrm{MtC})$. The largest net importers of carbon are Europe (100 MtC), East Asia (159 MtC), and West Asia (38 MtC). Figure 10 shows the top 10 trade flows for carbon in HWPs, crops, and livestock products. The flows for crops dominate, followed by the flows of HWPs, and livestock products are much smaller. The figure clearly shows there is a large net flux out of South America with the largest flows to Europe $(31 \mathrm{MtC})$, and to North America and East Asia (both $31 \mathrm{MtC}$ ). The large flows out of North America are almost completely compensated by large inflows. The largest flows are an export to East Asia (51 MtC), an import from East Asia (25 MtC), an export to Europe (17 MtC), and an import from South America $(15 \mathrm{MtC})$. East Asia also exports a large share to Europe $(20 \mathrm{MtC})$, and also has large imports from South East Asia (30 MtC).

The flows are considerable in magnitude, about one-third of fossil fuels, and could have a large effect on balancing regional carbon budgets. Our estimates are higher than the more common approach of apparent consumption (e.g. Ciais et al., 2008; Krausmann et al., 2008), thus we would suggest that lateral fluxes are larger than currently assumed. However, since we consider such a high level of processing, it may also be that we overestimate the traded flows of reduced carbon as some may be oxidised along the supply chain. We have not considered product decay (Pingoud et al., 2006; Cherubini et al., 2012), and this should be coupled with the biomass flows as some of the biomass will be oxidised before entering the trade flows (e.g. as waste in processing) and some will be oxidised over multiple years (decay of HWPs). Thus, further analysis of our results is required to determine the relevance for regional carbon budgets.

\section{Discussion}

Table 14 summarises the total carbon and flows of carbon between all 112 countries and regions analysed and the 12 RECCAP regions considered. We split the table into fossil fuel carbon and biomass carbon. Fossil fuel carbon is split into physically traded carbon, embodied carbon which additionally includes cement and gas flaring (hence the total carbon is different from the total fossil fuel carbon), and carbon in petroleum-based products. Physically traded fossil fuels are the largest source of internationally traded emissions, 
Table 12. The 2004 carbon in livestock products in each region (production), the amount and share exported, the consumption amount and share imported, and the difference between production and consumption (and exports and imports). Exports and imports only represent the trade between the RECCAP regions, and do not include the trade between countries within a region (e.g. Finland and Sweden). The shares are always in terms of production.

\begin{tabular}{|c|c|c|c|c|c|c|c|c|}
\hline \multirow[b]{2}{*}{ Region } & \multicolumn{3}{|c|}{ Production } & \multicolumn{3}{|c|}{ Consumption } & \multicolumn{2}{|c|}{ Balance } \\
\hline & $\begin{array}{r}\text { Production } \\
(\mathrm{MtC})\end{array}$ & $\begin{array}{r}\text { Exports } \\
(\mathrm{MtC})\end{array}$ & $\begin{array}{r}\text { Export } \\
\text { share }(\%)\end{array}$ & $\begin{array}{r}\text { Consumption } \\
(\mathrm{MtC})\end{array}$ & $\begin{array}{r}\text { Imports } \\
(\mathrm{MtC})\end{array}$ & $\begin{array}{r}\text { Import } \\
\text { share }(\%)\end{array}$ & $\begin{array}{r}\mathrm{Net} \\
(\mathrm{MtC})\end{array}$ & $\begin{array}{r}\text { Net } \\
\text { share }(\%)\end{array}$ \\
\hline Africa & 6.2 & 0.6 & 9 & 6.4 & 0.8 & 13 & -0.2 & -3 \\
\hline Oceania & 4.2 & 2.0 & 48 & 2.5 & 0.3 & 7 & 1.7 & 41 \\
\hline East Asia & 26.2 & 6.1 & 23 & 22.3 & 2.2 & 9 & 3.9 & 15 \\
\hline South East Asia & 3.4 & 0.5 & 14 & 3.6 & 0.7 & 20 & -0.2 & -6 \\
\hline South Asia & 11.8 & 0.7 & 6 & 11.3 & 0.2 & 2 & 0.6 & 5 \\
\hline Europe & 24.7 & 2.0 & 8 & 27.7 & 5.0 & 20 & -3.0 & -12 \\
\hline North America & 25.2 & 1.3 & 5 & 28.5 & 4.6 & 18 & -3.4 & -13 \\
\hline Russia & 6.0 & 0.3 & 6 & 6.5 & 0.9 & 15 & -0.5 & -9 \\
\hline South America & 12.8 & 3.0 & 24 & 10.0 & 0.2 & 2 & 2.8 & 22 \\
\hline Central America & 0.7 & 0.1 & 13 & 0.9 & 0.3 & 34 & -0.2 & -21 \\
\hline Eastern Europe & 2.1 & 0.4 & 21 & 2.0 & 0.3 & 16 & 0.1 & 5 \\
\hline West Asia & 5.8 & 0.2 & 4 & 7.5 & 1.9 & 32 & -1.6 & -28 \\
\hline Global & 129.2 & 17.4 & 13 & 129.2 & 17.4 & 13 & 0.0 & 0 \\
\hline
\end{tabular}

Table 13. The total biomass in carbon (HWPs, crops, livestock products) for production, consumption, exports, imports, and the balance (2004). All percentages are relative to the regional production.

\begin{tabular}{lrrr|rrr|rr}
\hline & \multicolumn{3}{c}{ Production } & \multicolumn{2}{c|}{ Consumption } & \multicolumn{2}{c}{ Balance } \\
\cline { 2 - 8 } Region & $\begin{array}{rrrrr}\text { Production } \\
(\mathrm{MtC})\end{array}$ & $\begin{array}{r}\text { Exports } \\
(\mathrm{MtC})\end{array}$ & $\begin{array}{r}\text { Export } \\
\text { share }(\%)\end{array}$ & $\begin{array}{r}\text { Consumption } \\
(\mathrm{MtC})\end{array}$ & $\begin{array}{r}\text { Imports } \\
(\mathrm{MtC})\end{array}$ & $\begin{array}{r}\text { Import } \\
\text { share }(\%)\end{array}$ & $\begin{array}{r}\text { Net } \\
(\mathrm{MtC})\end{array}$ & $\begin{array}{r}\text { Net } \\
\text { share }(\%)\end{array}$ \\
\hline Africa & 183.2 & 20.2 & 11 & 205.6 & 42.7 & 23 & -22.4 & -12 \\
Oceania & 37.8 & 22.8 & 60 & 22.5 & 7.5 & 20 & 15.3 & 40 \\
East Asia & 380.8 & 63.7 & 17 & 439.3 & 122.2 & 32 & -58.5 & -15 \\
South East Asia & 246.6 & 98.0 & 40 & 165.8 & 17.2 & 7 & 80.8 & 33 \\
South Asia & 227.4 & 12.4 & 5 & 234.0 & 18.9 & 8 & -6.6 & -3 \\
Europe & 259.8 & 29.0 & 11 & 359.9 & 129.0 & 50 & -100.1 & -39 \\
North America & 427.6 & 106.8 & 25 & 397.7 & 77.0 & 18 & 29.8 & 7 \\
Russia & 107.3 & 34.3 & 32 & 87.0 & 14.1 & 13 & 20.2 & 19 \\
South America & 218.3 & 91.7 & 42 & 135.8 & 9.1 & 4 & 82.5 & 38 \\
Central America & 17.0 & 5.0 & 30 & 23.0 & 11.0 & 65 & -6.0 & -35 \\
Eastern Europe & 33.2 & 8.7 & 26 & 30.9 & 6.4 & 19 & 2.3 & 7 \\
West Asia & 67.1 & 8.3 & 12 & 104.6 & 45.8 & 68 & -37.5 & -56 \\
\hline Global & 2206.2 & 500.9 & 23 & 2206.2 & 500.9 & 23 & 0.0 & 0 \\
\hline
\end{tabular}

at $2.7 \mathrm{GtC}$ from total emissions of $7.3 \mathrm{GtC}$ from combustion of fossil fuels $(37 \%)$. Emissions embodied in internationally traded goods and services from fossil fuel combustion, cement, and gas flaring, represents $1.7 \mathrm{GtC}(22 \%$ of all embodied emissions). Also associated with fossil fuels is the carbon in petroleum-derived products (plastics, fertilisers, and so on). The total carbon for petroleum-derived products is much smaller $(0.4 \mathrm{GtC})$, as are the trade flows $0.2 \mathrm{GtC}$ $(50 \%)$. For biomass carbon, we consider the carbon in industrial roundwood (HWPs), crops, and livestock products. At the aggregated level, the total trade flows in biomass carbon are about half the size of the embodied emissions. The largest contribution is from the international trade in crops $0.5 \mathrm{GtC}$ ( $31 \%$ of $1.7 \mathrm{GtC}$ total carbon); harvested wood products are much smaller with $0.1 \mathrm{GtC}$ ( $40 \%$ of $0.4 \mathrm{GtC}$ ), and carbon in livestock products smaller again with $0.03 \mathrm{GtC}(22 \%$ of $0.1 \mathrm{GtC})$. All of the flows are of sufficient magnitude to warrant deeper investigation, except perhaps the carbon in livestock products and petroleum-derived products. The carbon associated with fossil fuels is of most relevance to climate policy, while the carbon associated with biomass is relevant to both climate policy and to balancing regional carbon 
Table 14. A summary of the total and traded carbon associated with different activities (2004). Embodied carbon is emitted in the production of goods and services which are consumed in other countries, while all the other categories are physical flows of carbon. The total biomass includes HWPs, crops, and livestock products. The total trade considers international trade between all 112 countries and regions in our analysis, while RECCAP trade considers only the trade between the RECCAP regions.

\begin{tabular}{lr|rr|rr} 
& & \multicolumn{2}{c|}{ Total trade } & \multicolumn{2}{c}{ RECCAP trade } \\
\cline { 3 - 6 } & $\begin{array}{r}\text { Global } \\
\text { carbon (MtC) }\end{array}$ & $\begin{array}{r}\text { Traded } \\
\text { carbon (MtC) }\end{array}$ & $\begin{array}{r}\text { Share } \\
\text { traded (\%) }\end{array}$ & $\begin{array}{r}\text { Traded } \\
\text { carbon (MtC) }\end{array}$ & $\begin{array}{r}\text { Share } \\
\text { traded (\%) }\end{array}$ \\
\hline Fossil fuels & & & & & \\
\hline Physical carbon & 7293 & 2673 & 37 & 2090 & 29 \\
Embodied carbon* & 7427 & 1661 & 22 & 1199 & 16 \\
Petroleum products & 367 & 183 & 50 & 122 & 33 \\
\hline Biomass total & 2206 & 699 & 32 & 501 & 23 \\
\hline Livestock products & 129 & 28 & 22 & 17 & 13 \\
Crops & 1704 & 522 & 31 & 396 & 23 \\
HWPs & 373 & 149 & 40 & 88 & 24 \\
\hline
\end{tabular}

* Embodied carbon includes emissions from fossil fuel combustion, cement, and gas flaring and uses the GTAP7.1+NAMEA emission dataset. Thus, the total carbon differs to the total for physical carbon which necessarily uses the GTAP7.1 emission dataset and does not include cement production and gas flaring.

budgets. International trade is growing rapidly at the global level (Peters et al., 2009), indicating these flows will become more important in time.

There is a growing literature on the importance of embodied emissions in climate policy (Wiedmann et al., 2007; Peters and Hertwich, 2008b; Hertwich and Peters, 2009; Wiedmann, 2009; Nakano et al., 2009; Davis and Caldeira, 2010; Wiebe et al., 2012). Due to the rapid growth of international trade relative to economic activity, embodied emissions are growing over time (Nakano et al., 2009; Peters et al., 2011b; Caldeira and Davis, 2011; Wiebe et al., 2012). Much of the literature has focused on the issue of weak "carbon leakage" (Peters, 2010b). The studies robustly indicate that there are large, and increasing, flows of carbon between regions, with a net flow of embodied carbon from emerging to developed countries. Understanding these flows helps to understand regional emission drivers (Raupach et al., 2007; Le Quéré et al., 2009) and may assist in the design of climate policies (Peters and Hertwich, 2008a; Peters, 2008). Understanding embodied flows is also useful for the assessment of border taxes (Atkinson et al., 2011) and competitiveness concerns more broadly (Peters, 2010b). More recently, the importance of carbon flows in fossil fuels have been identified and compared with embodied carbon (Davis et al., 2011) and linked to human development indicators (Steinberger et al., 2012). The methods to estimate embodied emissions are well-established (Wiedmann et al., 2007; Wiedmann, 2009; Peters, 2010a), but independent studies often do not provide a clear comparison with other studies and explanations for differences. Thus, it appears estimates vary considerably between studies when differences may be caused by controllable difference in data and definitions, as shown here and elsewhere (Peters and Solli, 2010; Wiedmann et al., 2011).
While data and methods will improve over time with further research, the greatest need for further research is to identify how consumption-based emission estimates can be best utilised in policy settings.

The literature on physical flows of carbon in biomass flows is relatively small. There are only a few global studies, all of which have different objectives (Ciais et al., 2007; Krausmann et al., 2008; Erb et al., 2009; Kastner et al., 2011a). All of these studies have used the concept of "apparent consumption", and thus they do not include processing nor, with the exception of Kastner et al. (2011a), multiple levels of international trade. We believe our estimates are the first to link the most significant biomass flows to a standard and wellestablished attribution method. Since our analysis considers multiple levels of processing, our estimates of carbon flows are much higher than those reported in the cited literature. The high level of processing in our method may not, however, be suitable for all applications. In the case of regional carbon budgets, the entry of carbon to the atmosphere is relevant, and our method may allocate too much to exports due to temporal decay along the supply chain (e.g. waste). While our analysis on biomass flows was primarily in the context of regional carbon budgets, there are also policy applications. As for embodied carbon, understanding the regional drivers of biomass production and consumption is important (Krausmann et al., 2008; Erb et al., 2009). Tracking carbon in HWPs is already important in policy (Cowie et al., 2006; Pingoud et al., 2006), and has many parallels with concepts used in embodied carbon analysis. We believe carbon and biomass flows in international trade have currently received too little attention, and there is a need for more research on methodology, scientific applications, and understanding the implications for policy. 
We have covered most of the important flows of carbon associated with the economic system, however, we have not included carbon associated with deforestation. The carbon associated with deforestation is around $1.1 \mathrm{GtC} \mathrm{yr}^{-1}$ (Houghton et al., 2012), and international trade associated with deforestation is likely to be important (Zaks et al., 2009; Meyfroidt et al., 2010; DeFries et al., 2010). This is an important area for further research.

\section{Conclusions}

The physical and embodied carbon flows between regions are significant and important for scientific issues, such as balancing regional carbon budgets, and to understand regional emission drivers with relevance for policy issues. Comparisons between some of the key literature on embodied carbon shows that results are robust across studies. Differences between studies do not necessarily reflect the uncertainty in an individual estimate, but rather reflect controllable differences due to input data and definitions. A general finding supported by all studies is that there is a large and growing flow of embodied carbon from poor and emerging to developed countries. This is important to understand regional emission drivers and may have a variety of applications in policy. There are far fewer studies on the physical flows of carbon, and methodological differences are much larger leading to a larger spread between estimated carbon flows. We generally find higher estimates of carbon flows than in the literature since we consider a higher level of processing. Further research is needed by independent groups to resolve the differences between studies. We have not included carbon flows associated with deforestation, and this is an important area for further research. While further research is needed on methodological issues and comparability of studies, perhaps the largest gap in the literature is how to utilise the results to better support decision making in policy.

Acknowledgements. GPP and RMA acknowledge funding from the Norwegian Research Council project "Quantifying the global socio-economic and policy drivers for Brazil's contribution to global warming".

Edited by: J. Canadell

\section{References}

Ahmad, N. and Wyckoff, A.: Carbon dioxide emissions embodied in international trade of goods, Organisation for Economic Co-operation and Development (OECD), DSTI/DOC(2003)15, 2003.

Andres, R. J., Boden, T. A., Bréon, F.-M., Ciais, P., Davis, S., Erickson, D., Gregg, J. S., Jacobson, A., Marland, G., Miller, J., Oda, T., Olivier, J. G. J., Raupach, M. R., Rayner, P., and Treanton, K.: A synthesis of carbon dioxide emissions from fossil-fuel combustion, Biogeosciences, 9, 1845-1871, doi:10.5194/bg-9-18452012, 2012.

Andrew, R., Peters, G. P., and Lennox, J.: Approximation and regional aggregation in multi-regional input-output analysis for national carbon footprint accounting, Eco. Syst. Res., 21, 311-335, 2009.

Atkinson, G., Hamilton, K., Ruta, G., and Van Der Mensbrugghe, D.: Trade in "virtual carbon": Empirical results and implications for policy, Global Environmental Change, 21, 563-574, doi:10.1016/j.gloenvcha.2010.11.009, 2011.

Ayres, R. U. and Kneese, A. V.: Pollution, Consumption, and Externalities, American Economic Review, LIX, 282-296, 1969.

Boden, T. A., Marland, G., and Andres, R. J.: Global, Regional, and National Fossil-Fuel $\mathrm{CO}_{2}$ Emissions, Carbon Dioxide Information Analysis Center, Oak Ridge National Laboratory, U.S. Department of Energy, Oak Ridge, Tenn., U.S.A, 2009.

Boden, T. A., Marland, G., and Andres, R. J.: Global, Regional, and National Fossil-Fuel $\mathrm{CO}_{2}$ Emissions in Trends, in, Carbon Dioxide Information Analysis Center, Oak Ridge National Laboratory, U.S. Department of Energy, Oak Ridge, Tenn., U.S.A., 2011.

BP Statistical Review of World Energy June 2011: bp.com/ statisticalreview, 2011.

Bringezu, S., Schütz, H., Steger, S., and Baudisch, J.: International comparison of resource use and its relation to economic growth: The development of total material requirement, direct material inputs and hidden flows and the structure of TMR, Ecol. Econom., 51, 97-124, doi:10.1016/j.ecolecon.2004.04.010, 2004.

Bruckner, M., Giljum, S., Lutz, C., and Wiebe, K. S.: Materials embodied in international trade - Global material extraction and consumption between 1995 and 2005, Global Environ. Chang., doi:10.1016/j.gloenvcha.2012.03.011, 2012.

Bullard, C. W. and Sebald, A. V.: Monte Carlo Sensitivity Analysis of Input-Output Models, The Review of Economics and Statistics, 70, 708-712, 1988.

Caldeira, K. and Davis, S. J.: Accounting for carbon dioxide emissions: A matter of time, P. Natl. A. Sci., 108, 8533-8534, doi:10.1073/pnas.1106517108, 2011.

Canadell, J. G., Ciais, P., Gurney, K., Le Quéré, C., Piao, S., Raupach, M. R., and Sabine, C. L.: An International Effort to Quantify Regional Carbon Fluxes, Eos Trans. AGU, 92, doi:10.1029/2011eo100001, 2011.

Cherubini, F., Peters, G. P., Berntsen, T., Strømman, A. H., and Hertwich, E.: $\mathrm{CO}_{2}$ emissions from biomass combustion for bioenergy: atmospheric decay and contribution to global warming, GCB Bioenergy, 3, 413-426, doi:10.1111/j.17571707.2011.01102.x, 2011.

Cherubini, F., Guest, G., and Strømman, A. H.: Application of probability distributions to the modeling of biogenic $\mathrm{CO}_{2}$ 
fluxes in life cycle assessment, GCB Bioenergy, n/a-n/a, doi:10.1111/j.1757-1707.2011.01156.x, 2012.

Ciais, P., Bousquet, P., Freibauer, A., and Naegler, T.: Horizontal displacement of carbon associated with agriculture and its impacts on atmospheric $\mathrm{CO}_{2}$, Global Biogeochemical Cycles, 21, GB2014, doi:10.1029/2006GB002741, 2007.

Ciais, P., Borges, A. V., Abril, G., Meybeck, M., Folberth, G., Hauglustaine, D., and Janssens, I. A.: The impact of lateral carbon fluxes on the European carbon balance, Biogeosciences, 5, 1259-1271, doi:10.5194/bg-5-1259-2008, 2008.

Cowie, A., Pingoud, K., and Schlamadinger, B.: Stock changes or fluxes Resolving terminological confusion in the debate on landuse change and forestry, Climate Policy, 6, 161-179, 2006.

Davis, S. J. and Caldeira, K.: Consumption-based Accounting of $\mathrm{CO}_{2}$ Emissions, P. Natl. A. Sci., 107, 5687-5692, 2010.

Davis, S. J., Peters, G. P., and Caldeira, K.: The supply chain of CO2 emissions, P. Natl. A. Sci., 108, 18554-18559, doi:10.1073/pnas.1107409108, 2011.

DeFries, R. S., Rudel, T., Uriarte, M., and Hansen, M.: Deforestation driven by urban population growth and agricultural trade in the twenty-first century, Nat. Geosci, 3, 178-181, 2010.

Dittrich, M. and Bringezu, S.: The physical dimension of international trade: Part 1: Direct global flows between 1962 and 2005, Ecol. Econom., 69, 1838-1847, doi:10.1016/j.ecolecon.2010.04.023, 2010.

Erb, K.-H., Krausmann, F., Lucht, W., and Haberl, H.: Embodied HANPP: Mapping the spatial disconnect between global biomass production and consumption, Ecol. Econom., 63, 328-334, 2009.

European Commission: Manual for Air Emissions Accounts, Eurostat Methodologies and working papers, ISBN 978-92-7912205-7, Luxembourg, 2009.

European Commission: Emission Database for Global Atmospheric Research (EDGAR), release version 4.1, Joint Research Centre (JRC) and Netherlands Environmental Assessment Agency (PBL), 2011.

FAOSTAT: Production: http://faostat.fao.org/site/339/default.aspx, 2012a.

FAOSTAT: Forestry Products Definitions: http://faostat.fao. org/portals/_faostat/documents/forestproductsdefinitions.htm, 2012b.

FAOSTAT: Forestry: http://faostat.fao.org/site/630/Forestry.aspx, 2012c.

Foley, J. A., Ramankutty, N., Brauman, K. A., Cassidy, E. S., Gerber, J. S., Johnston, M., Mueller, N. D., O/'Connell, C., Ray, D. K., West, P. C., Balzer, C., Bennett, E. M., Carpenter, S. R., Hill, J., Monfreda, C., Polasky, S., Rockstrom, J., Sheehan, J., Siebert, S., Tilman, D., and Zaks, D. P. M.: Solutions for a cultivated planet, Nature, 478, 337-342, 2011.

Gallego, B. and Lenzen, M.: A consistent input-output formulation of shared producer and consumer responsibility, Eco. Syst. Res., 17, 365-391, 2005.

Haberl, H., Erb, K. H., Krausmann, F., Gaube, V., Bondeau, A., Plutzar, C., Gingrich, S., Lucht, W., and Fischer-Kowalski, M.: Quantifying and mapping the human appropriation of net primary production in earth's terrestrial ecosystems, P. Natl. A. Sci., 104, 12942-12947, doi:10.1073/pnas.0704243104, 2007.

Hertwich, E. G. and Peters, G. P.: Carbon Footprint of Nations: A Global, Trade-Linked Analysis, Environ. Sci. Tech., 43, 64146420, 2009.
Houghton, R. A., van der Werf, G. R., DeFries, R. S., Hansen, M. C., House, J. I., Le Quéré, C., Pongratz, J., and Ramankutty, N.: Chapter G2 Carbon emissions from land use and land-cover change, Biogeosciences Discuss., 9, 835-878, doi:10.5194/bgd9-835-2012, 2012.

Hubacek, K. and Giljum, S.: Applying physical input-output analysis to estimate land appropriation (ecological footprints) of international trade activities, Ecol. Econom., 44, 137-151, 2003.

IEA: Energy Statistics Manual, Organisation for Economic CoOperation and Development and International Energy Agency, 2005.

IEA: $\mathrm{CO}_{2}$ emissions from fuel combustion highlights International Energy Agency, Paris, 2011.

IPCC: IPCC Guidelines for National Greenhouse Gas Inventories, Prepared by the National Greenhouse Gas Inventories Programme, edited by: Eggleston, H. S., Buendia, L., Miwa, K., Ngara, T., and Tanabe, K., IGES, Japan, 2006.

Isard, W.: Interregional and regional input-output analysis, a model of a space economy, Review of Economics and Statistics, 33, 318-328, 1951.

Jensen, R. C.: The concept of accuracy in regional input-output models, Int. Regional Sci. Rev., 5, 139-154, 1980.

Jensen, R. C. and West, G. R.: The effect of relative coefficient size on input-output multipliers, Environ. Plann. A, 12, 659-670, 1980.

Kanemoto, K., Lenzen, M., Peters, G. P., Moran, D. D., and Geschke, A.: Frameworks for Comparing Emissions Associated with Production, Consumption, And International Trade, Environ. Sci. Technol., 46, 172-179, doi:10.1021/es202239t, 2012.

Kastner, T., Erb, K.-H., and Nonhebel, S.: International wood trade and forest change: A global analysis, Global Environmental Change, 21, 947-956, doi:10.1016/j.gloenvcha.2011.05.003, 2011a.

Kastner, T., Kastner, M., and Nonhebel, S.: Tracing distant environmental impacts of agricultural products from a consumer perspective, Ecol. Econom., 70, 1032-1040, doi:10.1016/j.ecolecon.2011.01.012, 2011b.

Krausmann, F., Erb, K.-H., Gingrich, S., Lauk, C., and Haberl, H.: Global patterns of socioeconomic biomass flows in the year 2000: A comprehensive assessment of supply, consumption and constraints, Ecol. Econom., 65, 471-487, doi:10.1016/j.ecolecon.2007.07.012, 2008.

Le Quéré, C., Raupach, M. R., Canadell, J. G., Marland, G., Bopp, L., Ciais, P., Conway, T. J., Doney, S. C., Feely, R., Foster, P., Friedlingstein, P., Houghton, R. A., House, J. I., Huntingford, C., Levy, P., Lomas, M. R., Majkut, J., Metzl, N., Ometto, J., Peters, G. P., Prentice, I. C., Randerson, J. T., Rödenbeck, C., Running, S. W., Sarmiento, J. L., Schuster, U., Sitch, S., Takahashi, T., Viovy, N., Werf, G. R. v. d., and Woodward, F. I.: Trends in the sources and sinks of carbon dioxide, Nat. Geosci., 2, 831-836, 2009.

Lee, H.-L.: An Emissions Data Base for Integrated Assessment of Climate Change Policy Using GTAP, Global Trade Analysis Project, 2008.

Lenzen, M., Wood, R., and Wiedmann, T.: Uncertainty analysis for Multi-Region Input-Output Models - a case study of the UK's carbon footprint, Eco. Syst. Res., 22, 43-63, 2010.

Lenzen, M.: Aggregation versus disaggregation in input-output analysis of the environment, Eco. Syst. Res., 23, 73-89, 
doi:10.1080/09535314.2010.548793, 2011.

Lenzen, M., Kanemoto, K., Moran, D., Geschke, A.: Mapping the Structure of the World Economy, Environ Sci. Technol., 46, 8374-8381, doi:10.1021/es300171x2012, 2012.

Leontief, W.: Environmental repercussions and the economic structure: An input-output approach, The Review of Economics and Statistics, 52, 262-271, 1970.

Leontief, W. W.: Quantitative input and output relations in the economic system of the United States, The Review of Economic Statistics, 18, 105-125, 1936.

Mayer, A. L., Kauppi, P. E., Angelstam, P. K., Zhang, Y., and Tikka, P. M.: Importing Timber, Exporting Ecological Impact, Science, 308, 359-360, 2005.

McDougall, R. and van Leeuwen, N.: International Marine Bunkers: An Attempt to Assign its Usage to the Right Countries, Global Trade Analysis Project, Purdue University, West Lafayette, United States, 2010.

Meyfroidt, P., Rudel, T. K., and Lambin, E. F.: Forest transitions, trade, and the global displacement of land use, P. Natl. A. Sci., 107, 20917-20922, doi:10.1073/pnas.1014773107, 2010.

Minx, J., Wiedmann, T., Wood, R., Peters, G. P., Lenzen, M., Owen, A., Scott, K., Barrett, J., Hubacek, K., Baiocchi, G., Paul, A., Dawkins, E., Briggs, J., Guan, D., Suh, S., and Ackermann, F.: Input-output analysis and carbon footprinting: An overview of regional and corporate applications, Eco. Syst. Res., 21, 187216, 2009.

Munksgaard, J. and Pedersen, K. A.: $\mathrm{CO}_{2}$ accounts for open economies: Producer or consumer responsibility?, Energy Policy, 29, 327-334, 2001.

Nakano, S., Okamura, A., Sakurai, N., Suzuki, M., Tojo, Y., and Yamano, N.: The measurement of $\mathrm{CO}_{2}$ embodiments in international trade: Evidence from the harmonized input-output and bilateral trade database, Organisation for Economic Co-operation and Development (OECD), 2009.

Narayanan, B. and Walmsley, T. L.: Global Trade, Assistance, and Production: The GTAP 7 Data Base, Center for Global Trade Analysis, Purdue University, 2008.

Oosterhaven, J.: A family of square and rectangular interregional input-output tables and models, Regional Science and Urban Economics, 14, 565-582, 1984.

Pedersen, G. O. and de Haan, M.: The System of Environmental and Economic Accounts-2003 and the Economic Relevance of Physical Flow Accounting, Journal of Industrial Ecology, 10, 1942, 2006.

Peters, G. P.: Efficient Algorithms for Life Cycle Assessment, Input-Output Analysis, and Monte-Carlo Analysis, International Journal of Life Cycle Assessment, 12, 373-380, 2007.

Peters, G. P.: From Production-Based to Consumption-Based National Emission Inventories, Ecol. Econom., 65, 13-23, 2008.

Peters, G. P. and Hertwich, E. G.: Post-Kyoto Greenhouse Gas Inventories: Production versus Consumption, Climatic Change, 86, 51-66, 2008a.

Peters, G. P. and Hertwich, E. G.: $\mathrm{CO}_{2}$ Embodied in International Trade with Implications for Global Climate Policy, Environ. Sci. Technol., 42, 1401-1407, 2008b.

Peters, G. P., Marland, G., Hertwich, E. G., Saikku, L., Rautiainen, A., and Kauppi, P. E.: Trade, Transport, and Sinks Extend the Carbon Dioxide Responsibility of Countries, Climatic Change, 97, 379-388, 2009.
Peters, G. P.: Carbon footprints and embodied carbon at multiple scales, Current Opinion on Environmental Sustainability, 2, 245250, 2010a.

Peters, G. P.: Managing Carbon Leakage, Carbon Management, 1, 35-37, 2010b.

Peters, G. P. and Solli, C.: Global carbon footprints: Methods and import/export corrected results from the Nordic countries in global carbon footprint studies, Nordic Council of Ministers, Copenhagen, 2010.

Peters, G. P., Andrew, R., and Lennox, J.: Constructing a multiregional input-output table using the GTAP database, Eco. Syst. Res., 23, 131-152, 2011a.

Peters, G. P., Minx, J. C., Weber, C. L., and Edenhofer, O.: Growth in emission transfers via international trade from 1990 to 2008 , P. Natl. A. Sci., 108, 8903-8908, 2011 b.

Peters, G. P., Marland, G., Quéré, C. L., Boden, T. A., Canadell, J. G., and Raupach, M. R.: Rapid growth in $\mathrm{CO}_{2}$ emissions after the 2008-2009 global financial crisis, Nature Climate Change, 2, 2-4, 2012.

Pingoud, K., Skog, K. E., Martino, D. L., Tonosaki, M., and Xiaoquan, Z.: Chapter 12: Harvested wood products. Volume 4, Agriculture, Forestry, and other Land Use (AFOLU). in: 2006 IPCC Guidelines for National Greenhouse Gas Inventories, IPCC National Greenhouse Gas Inventories Programme, 2006.

Raupach, M. R., Marland, G., Ciais, P., Le Quéré, C., Canadell, J. G., Klepper, G., and Field, C. B.: Global and regional drivers of accelerating $\mathrm{CO}_{2}$ emissions, P. Natl. A. Sci., 104, 10288-10293, doi:10.1073/pnas.0700609104, 2007.

SEEA: Integrated Environmental and Economic Accounting 2003, United Nations, European Commission, International Monetary Fund, Organisation for Economic Co-operation and Development, World Bank, 2003.

Steinberger, J. K., Krausmann, F., and Eisenmenger, N.: Global patterns of materials use: A socioeconomic and geophysical analysis, Ecol. Econom., 69, 1148-1158, doi:10.1016/j.ecolecon.2009.12.009, 2010.

Steinberger, J. K., Roberts, J. T., Peters, G. P., and Baiocchi, G.: Pathways of human development and carbon emissions embodied in trade, Nature Climate Change, 2, 81-85, doi:10.1038/nclimate1371, 2012.

$\mathrm{Su}$, B. and Ang, B. W.: Multi-region input-output analysis of $\mathrm{CO}_{2}$ emissions embodied in trade: The feedback effects, Ecol. Econom., 71, 42-53, doi:10.1016/j.ecolecon.2011.08.024, 2011.

Tukker, A., Poliakov, E., Heijungs, R., Hawkins, T., Neuwahl, F., Rueda-Cantuche, J. M., Giljum, S., Moll, S., Oosterhaven, J., and Bouwmeesterg, M.: Towards a global multi-regional environmentally extended input-output database, Ecol. Econom., 68, 1928-1937, 2009.

UNFCCC: Key GHG Data: Greenhouse Gas (GHG) Emissions Data, United Nations, 2012.

United Nations, Commission of the European Communities - Eurostat, International Monetary Fund, Organisation for Economic Co-operation and Development, and World Bank: System of National Accounts 1993, Brussels/Luxembourg, New York, Paris, Washington, D.C., 1993.

USDA: Composition of Foods Raw, Processed, Prepared USDA National Nutrient Database for Standard Reference, Release 23, 2010. 
Wiebe, K., Lutz, C., Bruckner, M., and Giljum, S.: Calculating energy-related $\mathrm{CO}_{2}$ emissions embodied in international trade using a global input-output model, Eco. Syst. Res., 24, doi:10.1080/09535314.2011.643293, 2012.

Wiedmann, T., Lenzen, M., Turner, K., and Barrett, J.: Examining the Global Environmental Impact of Regional Consumption Activities - Part 2: Review of input-output models for the assessment of environmental impacts embodied in trade, Ecol. Econom., 61, 15-26, 2007.

Wiedmann, T.: A review of recent multi-region input-output models used for consumption-based emissions and resource accounting, Ecol. Econom., 69, 211-222, 2009.

Wiedmann, T., Wilting, H. C., Lenzen, M., Lutter, S., and Palm, V.: Quo Vadis MRIO? Methodological, data and institutional requirements for multi-region input-output analysis, Ecol. Econom., 70, 1937-1945, doi:10.1016/j.ecolecon.2011.06.014, 2011.
Wiedmann, T. O., and Minx, J.: A definition of "carbon footprint", in: Ecol. Econom. Research Trends, edited by: Pertsova, C. C., Nova Science, Hauppauge, NY, 2008.

Wilting, H. C.: Sensitivity and uncertainty analysis in mrio modelling; some empirical results with regard to the dutch carbon footprint, Eco. Syst. Res., 24, 141-171, 10.1080/09535314.2011.628302, 2012.

Yamakawa, A. and Peters, G. P.: Using time-series to measure uncertainty in Environmental Input-Output Analysis, Eco. Syst. Res., 21, 337-362, 2009.

Zaks, D. P. M., Barford, C. C., Ramankutty, N., and Foley, J. A.: Producer and consumer responsibility for greenhouse gas emissions from agricultural production - a perspective from the Brazilian Amazon, Environ. Res. Lett., 4, 044010, doi:10.1088/1748-9326/4/4/044010, 2009. 